\title{
Multi-component diffusion mass transfer in nonselective IEX matrices with the noval displacement effect (NDE) for the concentration waves of the components - diffusants
}

\author{
Kalinitchev A.I. \\ Institute for Phys. Chem. \& El. Chem. , Rus. Acad. Sci., Moscow
}

Поступила в редакцию 31.01.2017 г.

There is presented the computerized modeling for the Diffusion Multicomponents $\left(i={ }_{1} \mathrm{~A} ;{ }_{2} \mathrm{~B} ; 3 \mathrm{C}\right)$ Mass Transfer (MMT) kinetics in the classical nonselective IEx Matrices. The Noval Displacement Effect (NDE) for the $\mathrm{X}_{i}$ (distance,Time)-concentration waves propagating in the IEx matrix is determined. The $\mathrm{W}(\mathrm{ave})^{+}$-concept is presented here for the $\mathrm{X}_{i}$-concentration waves of the $i$-components-diffusants which propagate (with multicomponent $\left\{\mathrm{D}_{\mathrm{A}}, \mathrm{D}_{\mathrm{B}}, \mathrm{D}_{\mathrm{C}}\right\}$-diffusivities) inside the nonselective IEx matrices. The NDE effect described is possible only for the definite conditions pointed in the last part of the publication $(\mathrm{S} .5,6)$.

In the result of the computerized simulation of the ternary $\left(\mathrm{R}_{1} \mathrm{~A}\right)_{\text {resin }}\left({ }_{2} \mathrm{~B}+{ }_{3} \mathrm{C}\right)_{\text {solution }}$ IEx Diffusion MMT there is demonstrated visually and obviously the Noval Displacement Effect (NDE) inside the r-bead \&ro-fiber matrices of the nonselective IEx resin for the distance-time behavior of the two invading $\mathrm{X}_{\mathrm{C}}, \mathrm{X}_{\mathrm{B}^{-}}$ concentration waves of the $i={ }_{2} \mathrm{~B},{ }_{3} \mathrm{C}$-components. The initial loading of the r-bead; ro-fiber of the IEx matrix is composed by the first $\left({ }_{1} \mathrm{~A}^{+}\right)$-component-diffusant. There is demonstrated the non-monotonic behavior of the kinetic $\mathrm{F}_{\mathrm{B}}(\mathrm{T})$-curve with the availability of the kinetic maximum- $\mathrm{F}_{\mathrm{B}}{ }^{\max }$ as the consequence of the NDEffect for the interactive $\mathrm{X}_{3 \mathrm{C}}, \mathrm{X}_{2 \mathrm{~B}}$-concentration waves which diffuse in the IEx r(ro)-matrices.

The original author's visualization method is used for the NDE description with the two «coupled» Figures, namely the pair of Figs. : [left $-\left\{\mathrm{X}_{i}\right\} \mid\left\{\mathrm{F}_{i}\right\}$-right $]$ arranged «in line\&abreast». The «coupled» pictures examples are presented visually in S.3. In this cases the $\left\{\mathrm{X}_{i}\right\}$-concentration waves (left) are arranged «in line\&abreast» with the $\left\{\mathrm{F}_{i}\right\}$-kinetic curves (right). Such new author's method of the «coupled Figures» namely: «left $-\left\{\mathrm{X}_{i}\right\} \mid\left\{\mathrm{F}_{i}\right\}$-right « plays the crucial role in the demonstration of the NDEffect for the diffusion IEx MMT in the non-selective ion exchangers.

Keywords: multicomponent, nonselective, ion exchange(r), mass transfer, partial differential equations, mass balance, computerized modeling(simulation), concentration waves, Noval Displacement Effect (NDE), wave concept $\left(\mathrm{W}^{+}\right)$

\section{Многокомпонентный диффузионный массоперенос в неселективных ИО (IEx) матрицах, включая Новый Вытеснительный Эфрект (НВЭ) для Хі-концентрационных волн і-компонентов-диффрузантов}

\author{
Калиничев А.И. \\ Институт физической химии и электрохимии РАН им. акад. А. Фрумкина, Москва \\ В работе представлено обобщенное теоретическое исследование Многокомпонентного Мас- \\ соПереноса (ММ) на основе численного компьютерного моделирования с решением диффузионных \\ уравнений многокомпонентного тернарного $\left(i={ }_{1} \mathrm{~A} ; 2 \mathrm{~B}{ }_{3} \mathrm{C}\right)$ материального баланса в частных производ-
}


ных. Для получения результатов диффузионного ММ в матрицах неселективных ионитов двух различных симметричных форм (r-зерно, rо-волокно) используется многокомпонентный диффузионный $\left\{\mathrm{D}_{\mathrm{A}} ; \mathrm{D}_{\mathrm{B}}, \mathrm{D}_{\mathrm{C}}\right\}$ тернарный ионный обмен $\left(\right.$ ИО): $\left(\mathrm{R}_{1} \mathrm{~A}^{+}\right)$смола $/\left({ }_{2} \mathrm{~B}^{+} ;{ }_{3} \mathrm{C}^{+}\right)$p-р в классических неселективных r,ro-матрицах ионообменников. На основе компьютерного моделирования диффузионного ММ показано, что при определенных условиях (указанных в последних разделах $\mathrm{S} .5,6)$ для $\left\{\mathrm{D}_{\mathrm{A}} ; \mathrm{D}_{\mathrm{B}}, \mathrm{D}_{\mathrm{C}}\right\}-$ диффузивностей реализуется Новый Вытеснительный Эффект (НВЭффект) при ИО для входящих в среду ионита и взаимодействующих в ней $\mathrm{X}_{\mathrm{C}}, \mathrm{X}_{\mathrm{B}}-$ концентрационных волн $\left({ }_{2} \mathrm{~B},{ }_{3} \mathrm{C}\right.$-компонентовдиффузантов).

Оригинальный авторский метод визуализации (включая подтверждение НВЭффекта) реализован с использованием двух обьединенных в «пару» рисунков: $\left\{\right.$ слева- $\mathrm{X}_{i}, \mid \mathrm{F}_{i^{-}}$справа $\}$, а именно: рисунок с изображением $\mathrm{X}_{i}$-концентрационных волн (слева), расположенный на одной линии (и в «паре») с другим рисунком, где изображены соответствующие $\mathrm{F}_{i}(\mathrm{~T})$-кинетические кривые (cnрава). Такой авторский метод визуализаџии кинетики ИО ММ - «на одной линии»: $\left\{\right.$ слева-Х $\mathrm{X}_{i} \mid \mathrm{F}_{l}-$ сnрава\} играет кардинальную роль, и позволяет выявить (и визуально продемонстрировать) причину НВЭффекта. Два наглядных примера НВЭффекта на «парных» рисунках, а именно: $\left\{\right.$ слева-Х $\mathrm{X}_{i} \mid \mathrm{F}_{i}-$ cnрава $\}$ даны здесь автором в представленной статье (в S.3).

Кроме того, в дополнение к указанному методу для визуализации результатов компьютерного моделирования (включая НВЭффект) также (как и ранее, начиная с 2003 г.) использован авторский метод Научных Компьютерных Анимаций (НКА). Метод НКАнимаций представлялся в авторских презентациях на ряде международных и всероссийских конференций в течение более 14 лет. В результате на практике показано, что НКА-визуализация распространения многокомпонентных $\mathrm{X}_{i-}$ концентрационных волн адекватно (и сравнительно легко) воспринимается научной аудиторией.

Авторские «НКАнимации» (т.е. «НКА.аvi»-видеофайлы) представляют собой анимационные много-цветные «фреймы-изображения» многокомпонентных $(i=1,2,3) \mathrm{X}_{i}$-концентрационных волн. Эти фреймы (с изображением движения многокомпонентных $\mathrm{X}_{i}$-волн) располагаются в видео-файле «НКА.avi» в порядке, соответствующем возрастанию текущих моментов времени $\left(\mathrm{T}_{1}<\mathrm{T}_{2}<\ldots\right)$. В видеофайлах «НКА.avi» для данного случая ИО (IEx) демонстрируется (визуализируется) распространение многокомпонентных $\mathrm{X}_{i}$-концентрационных волн в пространстве r,(ro)-матриц ионитов.

Ключевые слова: мультикомпонент, неселективность, ионообменник, массоперенос, уравнения в частных производных, массовый баланс, компьютерное моделирование, концентрационные волны, новый вытеснительный эффект (НВЭ), концепция волн $\left(\mathrm{W}^{+}\right)$

\section{Inroduction}

Previously the computerized simulations for the kinetics of the Multicomponent Mass Transfer (MMT) in the modern bi-functional NanoComposite (NC) matrices on the basis of the Author's Model with the two properties: I,Selectivity $\left(\mathrm{K}_{\mathrm{S}}\right)$ together with II, $\left\{\mathrm{D}_{i}\right\}$-multicomponent $\left\{\mathrm{D}_{i}\right\}$-Diffusivities for the $i$-components are presented.[1-5] The multicomponent diffusion MMT process in the bi-functional NC matrices is characterized by the two factors: Selectivities of the target components (I) \& $\left\{\mathrm{D}_{i}\right\}$-multicomponent diffusivities (II) of the $i$-components-diffusants.

The aim of this presentation is to consider the generalized theoretical approach including the fundamental aspects of the MMT kinetics in the various IEx nonselective rbead, ro-fiber matrices. The multicomponent Diffusion factor $\left(\left\{\mathrm{D}_{i}\right\}\right.$-diffusivities $)$ plays the cardinal role in the diffusion of the $\mathrm{X}_{i}$-concentration waves including the interference of this $\left\{\mathrm{X}_{i}\right\}$-waves inside the ion exchangers.

Two theoretical key concepts are used here in the IEx kinetic study: (1) $\mathrm{W}^{+}$-(wave) concept for the propagating and interfering $\mathrm{X}_{i}$-concentration waves; (2) Author's numerical computerized modeling of the MMT kinetics of the IEx process with the multicomponent $\left\{\mathrm{D}_{i}\right\}$-diffusivities of the $i$-components-diffusants $\left(i={ }_{1} \mathrm{~A},{ }_{2} \mathrm{~B},{ }_{3} \mathrm{C}\right.$, indexes to the left). The ternary Diffusion MMT is considered inside the nonselective IEx matrices of the various symmetrical shapes: spherical r-bead, or cylindrical ro-fiber. The NDEffect takes place during the MMT (at the definite conditions representing the definite relations between the $\left\{\mathrm{D}_{i}\right\}$-Diffusivities) only for the r,ro-shapes of the nonselective IEx matrices(Figs.1a,b). The NDEffect is not realized in the planar IEx matrix of the L-membrane. 
The variants of the nonselective IEx kinetics are considered on the basis of the calculated movements of the propagating $\mathrm{X}_{i}$-concentration waves $\left(\mathrm{W}^{+}\right.$-concept) without the Selectivity (S) factor (as the partial case with the only one multicomponent $\left\{\mathrm{D}_{i}\right\}$-Diffusion factor). The modeling for the generalized case-MMT in the contemporary NanoComposites: r-bead, ro-fiber, or planar L-membrane of the Selective(S) NC matrices is considered previously[1-5].

The fundamental well-known «Wave concept» (denoted here as $\mathrm{W}^{+}$) from the nonequilibrium thermodynamics approach [6] is used in the MMT kinetic process for the multi-component $\mathrm{X}_{i}$ (distance; Time)-concentration waves $\left(i={ }_{1} \mathrm{~A},{ }_{2} \mathrm{~B},{ }_{3} \mathrm{C}\right)$. The $\mathrm{X}_{i}(\mathrm{r}$,ro; Time)concentration waves of the $i$-components-diffusants propagate with the $\left\{\mathrm{D}_{i}\right\}$-diffusivities in the course of time (T) inside the nonselective IEx r,ro,-matrices[7,8].

The MMT process for the $i$-components-diffusants of the n-component mixture $(1 \leq i \leq \mathrm{n})$ is considered for the case when the appearing, (and then propagating) $\mathrm{X}_{\mathrm{i}}(\mathrm{r}$,ro; Time)-concentration waves (as the example the frontal profiles in Figs. 1a,b) which move in the course of time (T) inside the nonselective IEx r,(ro)-matrices from the contact: «re$\sin$ surface/external solution». The vectorial $\left.\mathrm{J}_{i r(\mathrm{ro})}\right)^{-}$mass fluxes into the separate particle ( $\mathrm{r}-$ bead, ro-fiber) of the IEx sorbent of the various symmetrical r-spherical, (ro)-cylindrical shapes are presented visually in Figs. 1a,b. A number of the explanatory illustrations for the IEx kinetic MMT process in the non-selective IEx matrices are presented below (Section 1) with the input $\mathbf{J}_{i}$-fluxes of the masses of the $i$-components-diffusants (Fig. 1a,b).

The additional significant explanatory illustrations for the $\mathrm{X}_{i}$-concentration waves are represented schematically (c, left) and visually (d,right) in Figs. 1(c,d). Figures 1(c,d) show the corresponding propagation of the concentration $X_{n}(r(r o) ; T)$-waves inside the IEx $\mathrm{r}(\mathrm{ro})$-matrices. As the simple examples such $\mathrm{X}_{\mathrm{n}}(\mathrm{r}(\mathrm{ro}) ; \mathrm{T})$-wave's frontal profiles are presented in Fig. 1c $\left(X_{n r, r o}\right)$, and Fig. 1d(experimental micro-picture $\left.X_{n r}\right)$.
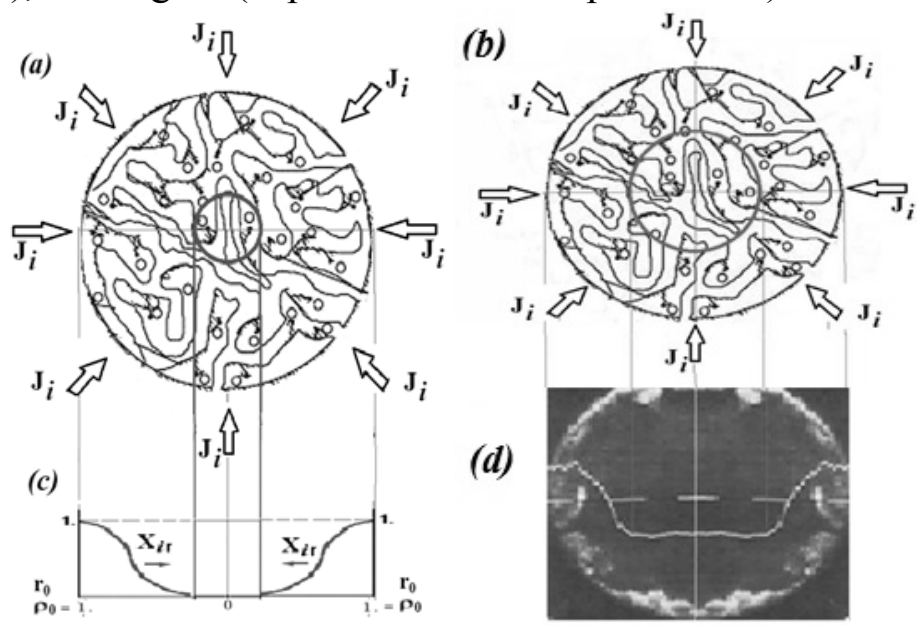

Fig. 1(a,c, left ; b,d, right). Illustrations for MMT inside the IEx matrix media (r;romatrices): (a,b) scheme of cuts of $\mathrm{r}$-sphere, (or ro-cylinder), with input $\mathrm{J}_{i,}(\mathrm{a} ; \mathrm{b})$-mass fluxes for $r$,(ro)-radial $X_{n r, r o}$-concentration waves; movements of $X_{n r,(r o)}$-waves to the center along r-radius $(a, b)$. Movement of the $X_{n r}$-waves to the center $(c, d)$ : along black arrows (c), and micropicture of the $\mathrm{X}_{\mathrm{nr}}$-wave $(\mathrm{Ni} / \mathrm{RH})$, [24] during the experiment for the non-selective IEx kinetics (white line, $\mathrm{d}$ ).

Besides Figures 1(a-d) show visually the input vectorial $\mathrm{J}_{(\mathrm{r}, \mathrm{r}) i}$-mass fluxes of the diffusing $i$-components with the corresponding $\left\{\mathrm{D}_{i}\right\}$-multi-Diffusivities. The directions of the $\mathrm{J}_{\mathrm{r},(\mathrm{ro})}$-vectors are pointed by the vectorial, radial arrows to the central core of the r-bead (ro-fiber) in Figs. 1a,b. The every disturbances of the $\mathrm{X}_{\mathrm{n}}$-concentrations for the every $i$ component $(1 \leq i \leq n)$ of the $n$-components mixture generate the propagating $X_{n}(r(r o) ; T)$ - 
concentration waves (frontal profiles, Figs. 1c,d) during the modeling of the NC or IEx MMT processes in the r,ro-matrices. $[1-5,7,8]$

The profiles of the propagating $X_{n r, r o}$-concentration waves inside the IEx r,(ro)matrices are presented appropriately in Figs. 1(c,d) placed under Figs.1(a,b) for the cut of the IEx r,(ro)-matrices. In Figs. 1(c,d) the radial, $\mathrm{X}_{\mathrm{nr}, \mathrm{ro}}$-concentration waves travel inside the IEx r,(ro)-matrices along r(ro)-radius to the r,(ro)-Center. The schemes for the NC, Lmembranes the $X_{n, r(r o)}$-concentration waves are shown appropriately together with the $\mathrm{NC}$ L-matrices in Figures placed in the publications.[1-5] The essential discrepancy between $\mathrm{L}$ - , and $\mathrm{r}(\mathrm{ro})$-matrices is that the input vectorial $\mathrm{J}_{\mathrm{r}(\mathrm{ro})}$-fluxes in Figs. 1(a-d) are "radial» while the $\mathrm{J}_{i \mathrm{~L}}$-fluxes in the planar L-membranes are «horizontal»[1-5].

\section{Simulation of MMT kinetics in IEx matrices. Generalized MMT partial differential equations \& key $\mathbf{W}^{+}$- concept}

The generalized phenomenological approach is described here (in S. 2) on the bases of the non-equilibrium thermodynamics approach [6] via the basic partial differential mass transfer n-Eqs. (3.A,below), which have been using for the nonselective IEx r(ro)-matrices (Figs. $1 \mathrm{a}, \mathrm{b}$ ). Such approach is implemented into the computerized modeling of the IEx MMT kinetic process. $[3,7,8]$

The multicomponent set of the generalized MMT mass balance n-Eqs.(3.A, S.3) is represented mathematically by the nonlinear mass diffusion partial differential equations. The nonlinear multicomponent n-system of the diffusion partial differential Eqs. (3.A) (with the accompanying relations: (3.1)-(3.5)) is executable only by the method of the computerized numerical mathematical simulation with the finite differences. Naturally that the corresponding boundary (3.6), and initial (3.7) conditions are introduced into the consideration for the various L; ro, r-matrices of the NC, or IEx materials for the computerized mathematical solution of the problem [1-5,7,8].

For the generalization of the theoretical results the most appropriate consideration is fulfilled via the dimensionless variables with the $\mathrm{X}_{\mathrm{n}}(\mathrm{r}, \mathrm{ro} ; \mathrm{T})$-concentration waves propagating along the dimensionless (r,(ro)-distances, see Figs. 1c,d) in the course of the dimensionless $\mathrm{T}$-time $\left(\mathrm{T}=\mathrm{D}_{0} \mathrm{t} /\left(\mathrm{r}_{0}\right)^{2}\right)$.

The mathematical approach used is presented via the computerized modeling of the MMT kinetics in the Sections 2,3 with the list of the positions: the equations and relations considered inside the IEx nonselective r,ro-matrices. Naturally that the total balance for all participating n-substances with the internal $\mathrm{J}_{i}$-fluxes $(1 \leq i \leq \mathrm{n}$, in Figs. $1 \mathrm{a}, \mathrm{b})$ is maintained during the computerized numerical simulations by the implicit finite difference technique for the r,(ro)-matrices considered (Fig.1a-d) $[1-5,7,8]$.

The modern approach with all mentioned postulates and equations of the created numerical solution of the multicomponent generalized partial differential MMT IEx n-Eqs. (3.A) mentioned together with the corresponding boundary and initial conditions, Eqs.(3.6,7)) has been applied (via the finite differences) for the computerized modeling with the numerical calculations of the propagating $X_{n}(r, r o ; T)$-concentration waves (Figs. $1 \mathrm{c}, \mathrm{d})$ mentioned. In result the mathematical solution of the IEx MMT balance equations describe the propagation of the interfering $\mathrm{X}_{i}$-concentration waves in the correspondence with the key multicomponent wave $\mathrm{W}^{+}$-concept presented.

The numerical technique is based on the implicit finite difference formulation (with the sweeping procedure) for the generalized parabolic partial difference diffusion IEx nEqs. (3.A) with the iteration technique including the multicomponent (mathematical) matrix calculations approach, including the multicomponent (mathematical) matrix inversions[ $1-5,7,8]$.

К алиничев А.И. / Сорбционные и хроматографические процессы. 2017. Т. 17. № 2 
The set of the author's corresponding computer Fortran programs has been composed for the simulation of the various MMT, IEx\&NC kinetics processes in the ncomponent systems.

The $\mathrm{X}_{\mathrm{n}}$ (distance; $\mathrm{T}^{\mathrm{S}}$ )-waves behavior is the result of the computer simulation via the elaborated Fortran programs for the propagation of the multicomponent $\mathrm{X}_{\mathrm{n}}$ (distance; $\mathrm{T}^{\mathrm{S}}$ )-concentration waves along the r,ro-distances (Figs. 1c,d) in the course of the discrete $\mathrm{T}^{\mathrm{S}}$-time$[1-5,7,8]$.

The behavior of the multicomponent IEx, MMT systems are described effectively on the basis of the conceptual wave $\mathrm{W}^{+}$-approach [6] describing the multicomponent propagating waves with $\mathrm{X}_{\mathrm{n}, i \text {;ro, }}(\mathrm{T})$ )-concentration profiles (Figs. 1c,d) in the IEx matrices. (There is considered here the non-selective IEx MMT kinetics $[3,7,8]$ as the partial case of the generalized NC, MMT process [1-5]).

The IEx MMT approach is in the connection with the general framework of the various considerations based on the wave $\mathrm{W}^{+}$-concept. Previously the multicomponent "wave" theoretical approach has been used especially effectively for the dynamic (chromatographic) systems[9-19].

Thus, the computerized investigations of the NC\&IEx MMT kinetics [1-5,7,8] have been realized in cooperation with the co-working $\left\{\mathrm{D}_{i}\right\}$-multiDiffusion influence in the pores of the matrices for the $i, \mathrm{j}$-components. There are included into the consideration the properties of the $\mathrm{NC}[1-5]$, and IEx $[3,7,8]$ models with using the effective key wave $\mathrm{W}^{+}$concept including the $\mathrm{X}_{\text {nro, }}$-concentration waves behavior. The difference and similarity in the concentration waves behavior between the two kinds of the dynamic (in chromatography), and NC kinetic systems are described and summarized [1-5].

In the excellent monograph [9] the dynamic behavior of the $X_{n}$-concentration waves in the chromatographic column (filter) is described in the multicomponent chromatographic, and ideal dynamic systems. In such ideal cases (without the dispersion factors in the chromatographic filters) the problem is considered for the dynamic $\mathrm{X}_{\mathbf{n}}$-concentration waves with the multicomponent competitive Langmuir sorption (or IEx) isotherms with the constant separation coefficients[9,11,14-16].

The mathematical theory of the hyperbolic partial differential equations with the application of the mathematical h-transformation approach (or in other mathematical terminology: Rieman invariants) is effectively used by the authors[9] for the description of the propagation of the multicomponent ideal $\mathrm{X}_{\mathrm{n}}$-concentration waves on the basis of the wave concept $[9,11]$.

\section{Main mathematical formulation of the IEx, MMT problem with the diffusion partial differential equations}

The multicomponent diffusion $\mathrm{X}_{\mathrm{nL} ; \mathrm{ro,r}}(\mathrm{T})$-concentration waves with their propagation (along L;ro,r -distances) (visual examples in Figs. 1c,d) including the interference of the concentration $\mathrm{X}_{\mathrm{nL} ; \mathrm{ro,r}}(\mathrm{T})$-waves inside the bi-functional $\mathrm{NC}$ L;ro,r-matrices play the decisive role in the description of the diffusion NC, and IEx MMT kinetics process.[1$5,7,8]$ The IEx MMT kinetic process is considered here as the partial case of the general NC kinetics in the bi-functional NC matrices[1-5]. Therefore additionally to the short review above this well-known and widely used «wave» approach (the key wave $\mathrm{W}^{+}$-concept) for the dynamic (chromatographic) systems [9-19], and for the multi-component NC, and IEx kinetics systems $[1-5,7,8]$ is shortly considered in S. 4, below. The $\mathrm{W}^{+}$-wave approach represents the fundamental part of the thermodynamics of the irreversible processes[6].

Naturally that the multicomponent diffusion $\mathrm{X}_{\mathrm{nL} \text { (ro)r }}(\mathrm{T})$-concentration kinetic waves may propagate in the pores of the usual IEx medium due to the such driving forces as the

Калиничев А.И. / Сорбционные и хроматографические процессы. 2017. Т. 17. № 2 
concentration gradients with the additional effect of the general electric field gradient (grad $\Phi$ in Eqs.(3.4)) with the $\left\{\mathrm{D}_{i}\right\}$-coefficients as the multi-Diffusion factor. The corresponding explanation with Eqs.(3.4), (3.5) and with the IEx kinetics examples are presented visually in Figs. 3a,b-5a,b in S.5 below.

The detailed description of the IEx MMT kinetics by the MMT system of the basic partial differential n-Eqs. (3.A) with the corresponding relationships (3.2)-(3.7) is given (here in S.3). According to the IEx MMT diffusion kinetic partial differential mass balance $\mathrm{n}^{\text {th }}$-Eqs. $(\mathrm{n}=1, i, .$.$) in the course of T-time with the ro,r-distances in the IEx matrices are$ usually presented in generalized form as follows $[3,7,8]$

$$
\partial \mathrm{X}_{\mathrm{n}} / \partial \mathrm{T}=\underbrace{-\operatorname{div}\left\{\mathrm{J}_{\mathrm{n}}\right\}}, \mathrm{n}=1, . \mathrm{m}, i, . . \mathrm{j}, . . .
$$

Change of n-mass [Diffusion term with $\mathrm{J}_{\mathrm{n}}$-mass fluxes]

The IEx kinetics MMT partial differential n-Eqs. (3.A) have the mathematical distinctions which in respect to the various IEx matrix shapes (r-sphere, ro-fiber) are conditioned in the distinct mathematical expressions for the differential operators: $\operatorname{grad}_{\mathrm{r}, \mathrm{ro}}\left(\mathrm{X}_{\mathrm{n}}\right)$, and $\operatorname{div}_{\mathrm{r}, \mathrm{ro}}\left\{\mathrm{J}_{\mathrm{n}}\right\}$. The rather simple physical sense of the generalized MMT n-Eqs. (3.A) is explained and illustrated visually in the author's publications $[1-5,7,8]$

Besides in the author's computerized simulation [1-5,7.8] there are used the fundamental Nernst-Planck n-relationships (3.4) [6] for the diffusion vectorial $J_{i, j}$-fluxes in the n-Eqs.(3.A) for the each diffusing $i, j$-components with the constant multi-Diffusion coefficients: $\left\{\mathrm{D}_{i, j}\right\}$ - Diffusivities. The classical Nernst-Plank relationship for the $\mathrm{J}_{i, j}$-fluxes in the IEx matrices of the $i, j$-components describes the diffusion not only for the charged $i, j-$ components but for the not charged one $\left(\mathrm{z}_{j}=0\right)$ also [20-28]:

$$
\mathrm{J}_{e}=\mathrm{J}_{e}{ }^{\mathrm{X}}+\mathrm{J}_{\mathrm{e}}^{\mathrm{el}}=-\mathrm{D}_{e}\left\{\operatorname{grad} \mathrm{X}_{e}+(\mathrm{F} / \mathrm{RT}) \mathrm{z}_{e} \mathrm{X}_{e} \operatorname{grad} \Phi\right\}, e=i, . . \mathrm{j} . .
$$

where $\mathrm{J}_{e}$ are mass fluxes for the multi-Diffusion of the e-components (with $\left\{\mathrm{D}_{i, j}\right\}$ diffusivities; $\left.\mathrm{D}_{i, j}>0\right)$.

The Diffusion $\mathrm{J}_{e^{-}}$-fluxes (3.5) (Figs.1a,b) for the $e$-components are composed from the two characterizing terms: $(a) \mathrm{J}_{e}{ }^{\mathrm{X}}$ is the vectorial flux with the driving force conditioned by the $\mathrm{X}_{e}$-concentration gradients $\left(-\mathrm{D}_{e} \operatorname{grad} \mathrm{X}_{e}\right)$, and $(b) \mathrm{J}_{\mathrm{e}}{ }^{\mathrm{el}}$ is the additional vectorial flux with the driving force conditioned by the electrical $\Phi$-potential gradient: $-\mathrm{D}_{e}(\mathrm{~F} / \mathrm{RT}) \mathrm{z}_{e} \mathrm{X}_{e}$ $\operatorname{grad} \Phi$.

In result the classical Nernst-Plank relations (3.4) in the IEx MMT partial differential n-Eqs. (3.A) describe the diffusion MMT for the all n-components.

The material balances in n-Eqs. (3.A) for the multicomponent kinetic IEx system should be supplemented by the two additional conditions [20-28]:

for the electroneutrality condition

$$
\operatorname{SUM}_{\mathrm{n}}\left(\mathrm{z}_{n} \mathrm{X}_{n}\right)=1
$$

for the condition of the absence of the electric current

$$
\operatorname{SUM}_{\mathbf{n}}\left(\mathrm{Z}_{\mathbf{n}} \mathbf{J}_{\mathbf{n}}\right)=0
$$

As usual, due to the known algebraic transformation the influence of the gradient of the electric field $(\operatorname{grad} \Phi)$ is expressed mathematically[6,21,22] via the sum of the other $\mathrm{X}_{\mathrm{n}}$-concentration gradients by using the absence of the electric current relationship (3.3). [6,20-28] Then in the result the $\mathrm{J}_{\mathrm{n}}$-fluxes $(\mathrm{n}=1,2, \ldots)$ are described by its own gradient $\left(\operatorname{grad} \mathrm{X}_{\mathrm{n}}\right)$ with the addition of the multicomponent superposition of $\mathrm{X}_{i}$-concentrations gradients $\left(\operatorname{grad} \mathrm{X}_{i}\right)$ (3.4),(3.5).[6, 20-28] Such well-known superposition of the gradients $(3.4 ; 3.5)$ obtained by this method of exclusion is called the "diffusion potential" in the theory of the irreversible thermodynamics $[6,20,21]$

$$
\text { - }(\mathrm{F} / \mathrm{RT}) \operatorname{grad} \boldsymbol{\Phi}=\mathrm{SUM}_{i}\left(\mathrm{D}_{\mathrm{i}} \mathrm{Z}_{\mathrm{i}} \operatorname{grad} \mathrm{X}_{\mathrm{i}}\right) / \mathrm{SUM}_{\mathrm{i}}\left(\mathrm{D}_{i} \mathrm{z}_{\mathrm{i}}^{2} \mathrm{X}_{i}\right), \mathrm{i}=1,2 \ldots
$$


The fundamental Nernst-Plank relationships (3.1) reflect the dependence of the $J_{n^{-}}$ fluxes from the concentration gradients together with the integral co-influence of the electric field gradient, (grad $\Phi$ in Eqn.(3.4)) [6, 20,21,26,28].

The relationship (3.4) gives the possibility to eliminate formally (mathematically) the gradient of the electric potential $(\Phi)$ from the mathematical consideration by using the two (3.2), (3.3) relationships, with the final result

$$
\mathrm{J}_{e}=\mathrm{J}_{\mathrm{e}}{ }^{\mathrm{X}}+\mathrm{J}_{\mathrm{e}}^{\mathrm{el}}=-\mathrm{D}_{e}\left\{\operatorname{grad} \mathrm{X}_{e}+\mathrm{SUM}_{i}\left(\mathrm{D}_{\mathrm{i}} \mathrm{Z}_{\mathrm{i}} \operatorname{grad} \mathrm{X}_{\mathrm{i}}\right) / \mathrm{SUM}_{\mathrm{i}}\left(\mathrm{D}_{i} \mathrm{Z}_{\mathrm{i}}^{2} \mathrm{X}_{i}\right)\right\}
$$

In result the first term $\mathrm{J}_{\mathrm{e}} \mathrm{X}$ in the Eq. (3.5) is conditioned by the individual diffusion $\mathrm{D}_{e}$ of the $e$-component, and the second $\mathrm{J}_{\mathrm{e}}^{\mathrm{el}}$ summand represents the influence of the electric field gradient ( $\operatorname{grad} \Phi)$ ). Thus the second term in Eq.(3.5) shows the interferences of the $\mathrm{X}_{i^{-}}$ concentration waves propagating in the IEx, (and in the bi-functional NC) matrices due to the common electric field.

For the computerized solution of the IEx, MMT system the problem should be completed by the accounting of the boundary (3.6) and the initial (3.7) conditions:

boundary $\left(\mathrm{r}_{0}, \mathrm{ro}_{0}, \mathrm{~L}_{0}\right.$, and $\mathrm{r}$, ro, $\left.\mathrm{L} \rightarrow 0\right)$ conditions

$$
\begin{aligned}
& \text { at } \mathrm{r}_{0}, \mathrm{ro}_{0}, \mathrm{~L}_{0}=1 ; \mathrm{X}_{\mathbf{n}}=\mathrm{X}_{\mathbf{n}}{ }^{0}, \text { and } \\
& \quad \text { at } r, r o, L \rightarrow 0 ; \mathrm{r}^{2}\left(\partial \mathrm{X}_{\mathbf{n}} / \partial \mathrm{r}\right) \rightarrow 0 ; \operatorname{ro}\left(\partial \mathrm{X}_{i} / \partial r o\right) \rightarrow 0 ;\left(\partial \mathrm{X}_{i} / \partial \mathrm{L}\right)=0 \\
& \quad \text { initial conditions }: \text { at } \mathrm{T}=0 ; \mathrm{X}_{\mathbf{n}}=\mathrm{X}_{\mathbf{n}}{ }^{00}
\end{aligned}
$$

The electro-neutrality condition (3.2) should be fulfilled also for the boundaries: $\mathrm{r}_{0}$, $\mathrm{ro}_{0}, \mathrm{~L}_{0}=1$, and 0 (3.6), as well as at the initial $(\mathrm{T}=0)$ conditions (3.7).

The obtained results of the computerized simulation with the n-Eqs.(3.A) are presented via the well-known, key multi-component concentration "waves", $\mathrm{W}^{+}$-concept mentioned. [1-5] The short review of the description of the wave $\mathrm{W}^{+}$-concept with its applications is presented below in the next S.4.

\section{Concentration wave key $\mathbf{W}^{+}$-concept in the multicomponent Diffusion IEx MMT kinetics and dynamics}

The obtained results of the computerized simulation on the basis of the created author's contemporary multicomponent bi-functional NC Model [1-5] are presented via the well-known multicomponent «concentration waves» via the key $\mathrm{W}^{+}$-concept repeatedly mentioned.

The $\mathrm{X}_{\mathrm{n}}\left(\right.$ distance; $\left.\mathrm{T}^{\mathrm{S}}\right)$-concentration waves arise and propagate along the distances: (r,(ro)-radius, or L-thickness; dimensionless) inside the IEx or NC L;ro,r-matrices during the MMT kinetics process. The multicomponent $X_{n}\left(\right.$ distance; $\left.T^{S}\right)$ waves with their propagation play the decisive role in the description of the bi-functional $\mathrm{NC}$, or mono-functional IEx MMT kinetics. [1-5,7,8] Therefore this well-known and widely used «wave» $\mathrm{W}^{+}$approach (especially in the theory of multicomponent chromatography [9-19] ) is shortly reviewed below including the next S. 4.1.

The key wave $\mathrm{W}^{+}$-concept of «multicomponent waves» is widely used in the theoretical description for many scientific fields of the MMT for various kinetic and dynamic systems. The «multicomponent waves» $\mathrm{W}^{+}$-concept has wide area for the applications in the such research fields, as percolation processes[9-15], mechanics of liquids, gas dynamics, [29] theory of burning and even street traffic $[15,16,30]$. The term «wave» (here, the key $\mathrm{W}^{+}$-concept) has been used in all these publications[1-31] including the mentioned excellent monograph[9], and the books[15,29-31] concerned with shock waves, car traffic, and kinematic waves. There are phenomenological concepts potentially common to all filtration processes, which can also be extended to a whole series of migration phenomena such as chromatography, sedimentation, electrophoresis and some others [9-31]. 
The review [17], and additionally the presentations [18,19] published by the author in cooperation with prof. W. Hoell (Karlsruhe Res. Center, Germany) include the application of the wave concept in the multicomponent dynamics (chromatography) with the description of the SCT (Surface Complexation Theory) Model. The SCT-Model for the multicomponent IEx equilibrium had been elaborated by prof. W. Hoell group at the end of the last century (see Refs. in the review[17]).

In previous manuscripts [1-5] the described postulates of the mathematical modern $\mathrm{NC}$ bi-functional Model created, and $\mathrm{MAL}_{\mathrm{S}}$ relations for the chemical reactions equilibrium $[1-5,32]$ have been implemented into the mathematical description of the MMT,NC kinetics process together with the all relationships including the mass balance partial differential n-Eqs (3.A), electro-neutrality condition (3.5), classical Nernst - Plank equations (3.4) for the $J_{n}$ fluxes of the n-components (S.3).

All the computerized calculations have been obtained by using the dimensionless values, including $\mathrm{X}_{\mathrm{n}}$-concentrations; $\mathrm{D}_{\mathrm{n}}$-diffusion coefficients; $\mathrm{K}_{\mathrm{S}}$-constants of chemical association-dissociation $\mathrm{MAL}_{\mathrm{S}}$ reactions.[1-5]. The MMT kinetics in the IEx kinetics include the multicomponent $\mathrm{X}_{\mathrm{n}}$-concentration waves propagation along the dimensionless distance: $\mathrm{L}$,(ro), $\mathrm{r}$ in the course of the dimensionless time $\left(\mathrm{T}=\mathrm{D}_{0} \mathrm{t} / \mathrm{r}_{0}{ }^{2}\right)[1-5,7,8,32]$.

\subsection{Coherence state of the multicomponent $X_{n}$-concentration waves}

The coherence conditions for the $X_{n}$-concentration waves define a special regime in the propagation of the multicomponent concentration waves in the chromatographic, dynamic systems in which all the $X_{n}$-concentration waves of the $n$-components mixture move synchronously.[9-12] The concept of the coherence describes the states of the chromatographic systems which they tend to attain similarly to the way that closed system tend to a state of equilibrium, while open system with a fixed boundaries and constant boundary conditions tend to attain stationary states[9-16].

The concept of coherence was developed, and generalized by F. Helfferich with reference to the sorption waves[10-13]. This $\mathrm{W}^{+}$-concept makes it possible to treat qualitatively, and to calculate in principle quantitatively the multi-component concentration waves in a chromatographic systems under the arbitrary initial and boundary conditions. On the D. Tondeur opinion $[12,13]$, «the coherence is one of the most deep reaching and powerful concept in process dynamics, at least as far as the multicomponent systems are concerned»[13].

More generally coherence is considered as a state or a rather dynamical regime toward which a dynamic system will naturally tend when relaxing after a finite time[9-13]. However, coherence not only refers to the end state of relaxation after a perturbation but also to the relaxation occurs the way in which an incoherent perturbation breaks up into the coherent modes[10,11].

The global concept of coherence [9-13] indicates the direction in which the development of the multicomponent system advances towards the final coherent state. The coherence definition with its physical sense has been explained by F. Helfferich clearly[10] .

\section{waves}

4.2. Interference Effects for the multicomponent $X_{n}$-concentration

Previously the multicomponent $\mathrm{W}^{+}$-concept (for the $\mathrm{X}_{\mathbf{n}}$ (distance; T-time)concentration wave) has been considered not only for the IEx MMT kinetics mass transfer[7,8] (see this manuscript) but for the mass transfer dynamics in the sorption, and Ion

Калиничев А.И. / Сорбционные и хроматографические процессы. 2017. Т. 17. № 2 
Exchange (IEx) systems also (sometimes even with the good results).[9-19] Therefore the propagating multicomponent $\mathrm{X}_{\text {ndistance }}\left(\mathrm{T}\right.$-time)-concentration waves with the key wave $\mathrm{W}^{+}$concept should be considered. It should be stressed as one of the main feature of the MMT, $\mathrm{NC}(\&$ IEx in S.5) kinetics in this manuscript (and in $[1-5,7,8] \&$ S.5.

The difference between the propagation of the multicomponent $\mathrm{X}_{\text {ndistance }}(\mathrm{T})$ concentration waves in the kinetics and dynamics of the MMT systems is rather evident though the travelling multicomponent $\mathrm{X}_{\text {idistance }}(\mathrm{T})$-concentration waves are originated in both cases. However in addition, there are the essential differences for the comparing of the $\mathrm{X}_{(i) \text { distance }}(\mathrm{T})$-concentration waves behavior in the IEx MMT dynamics and kinetics systems:

a) In the IEx dynamics systems, as a rule, the travelling concentration waves (especially in the theory of the multicomponent chromatography[9]) used to reach the stage named as «coherence» (which is introduced by F. Helfferich in [10]). This important generalized concept is discussed in many publications[9-16] (see also above here). In this case the linear sizes in the chromatography system are large. Therefore for the dynamics the multicomponent $X_{n}$-concentration waves achieve the so called «coherent state»[9-13]. In the coherent state the $\mathrm{X}_{\mathrm{n}}$-multicomponent waves are separated by the concentration plateaus and move synchronously[9-16].

b) In the diffusion multicomponent MMT NC \&IEx kinetics systems (like in the multicomponent NC kinetics considered previously), the behavior of the $\mathrm{X}_{\mathrm{iL}(\mathrm{r}) \mathrm{r}}(\mathrm{T})$-waves and its interpretation differ in the presence of the diffusion phenomenon (even in the absence of the chemical reactions (Selectivity I)). Due to the short ( $L ;$ ro,r $r$ )-distances the propagation of the diffusion $\mathrm{X}_{\mathrm{i}, L(\mathrm{r})) r}(\mathrm{~T})$-concentration waves takes place in the NC\&IEx MMT kinetics systems without the formation of the concentration plateaus between the $\mathrm{X}_{\mathbf{i}, L(\mathrm{r}) r)}(\mathrm{T})$-waves[1-5,7,8]. In this case, due to a limited small size (like: L;ro,r) of the vari-

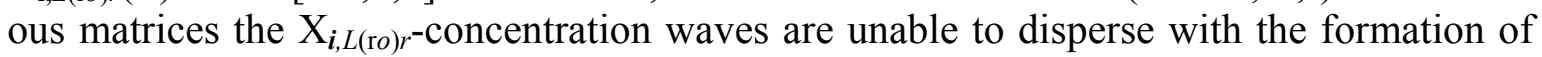
the concentration plateaus.

Therefore, the coherent state (or else the stationary state) might not be attainable in all NC\&IEx kinetics variants of the MMT process due to the short distance covered by the $\mathrm{X}_{\mathrm{n}}$-waves in the MMT kinetics systems. However, it is naturally that in the case of the MMT, NC\&IEx kinetics, the effect of the interference of the multicomponent diffusion kinetic $\mathrm{X}_{i}$-concentration waves takes place[1,5,7,8,20-28]. All the results of the computerized MMT, NC(or IEx) kinetics simulations show the essential meaning of the $\mathrm{X}_{\mathrm{i} L(\mathrm{ro}) r}(\mathrm{~T})$ concentration waves interference in the course of time (T) $[1-5,7,8]$.

\section{Ternary $\left\{D_{i}\right\}$-Diffusion kinetics, including NDE in the non-selective IExchangers}

Before the consideration of the multicomponent (ternary) nonselective IEx diffusion kinetics there is demonstrated visually the one $i$-component $(i=1) \mathrm{X}_{i}$-concentration wave behavior (Figs 2a,b, below) for the two simple binary IEx variants. These variants of the one $i$-component $(i=1)$ IEx kinetics are corresponded to the binary $(i / \mathrm{j})$ IEx in the $\mathrm{r}$ bead matrix[24]. In Figures 2a,b the two experimental SEM micro-pictures are shown as the illustration of the propagating diffusion $\mathrm{X}_{i \mathrm{r}}$-concentration Ni-wave profile $(i=1)$ for the binary IEx $(\mathrm{Ni} / \mathrm{Rj})$ inside the r-bead matrix.

Figures 2a,b show the simple one component $(i=1) \mathrm{X}_{\mathrm{Ni}}$-waves (SEM profiles depicted by the light lines) for the two types of the binary IEx : (a) left - nonselective IEx $\left(\mathrm{H}^{+} / \mathrm{Ni}^{2+}\right)$, ; (b) right - selective IEx $\left(\mathrm{Ni}^{2+} / \mathrm{Na}^{+}\right)[24]$. The SEM micro-pictures (Figs.2a,left; $\mathrm{b}$,right) show the diffusion $\mathrm{r}$-spherical $\mathrm{X}_{\mathrm{Ni}(\mathrm{r})}$-wave propagation of the two types $(\mathrm{a}, \mathrm{b})$ of the 
invading one component (i.e. $i=1$, binary IEx) $\mathrm{X}_{\mathrm{Ni}, \mathrm{r}}$ r-concentration waves in r-sphere. The experimental selective IEx, SEM micro-picture (Fig. 2b, right) presents additionally the illustration of the visual structure of the selective IEx resin inside and outside of the visual $\mathrm{Na}\left(\mathrm{A}^{+}\right) / \mathrm{Ni}\left(\mathrm{B}^{+}\right) \mathrm{r}-$ spherical boundary.

Comparison of the nonselective (a) and selective (b) IEx with the corresponding experimental concentration waves is presented visually in Figs. 2 a,b (below)

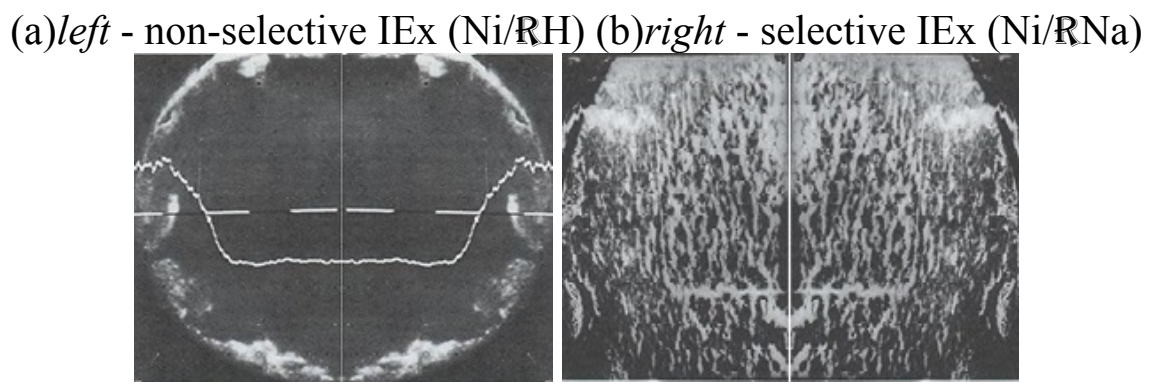

Fig. 2 a,b. Experimental SEM micro-pictures with binary (Ni/Rj) Diffusion IEx: propagation of the invading $\mathrm{X}_{\mathrm{N} i, \mathrm{r}}$-concentration waves to the r-Center: (a), left -non-

selective IEx (RH/Ni); (b),right-selective IEx $(\mathrm{RNa} / \mathrm{Ni})$. Light lines $(\mathrm{a}, \mathrm{b}): \mathrm{X}_{\mathrm{Ni}, \mathrm{r}^{-}}$ concentration waves-profiles. Micro-pictures for two kinds of IEx: (a) spreading diffusion $\mathrm{X}_{\mathrm{Ni}, \mathrm{r}}$-wave, non-selective IEx; (b) sharp $\mathrm{X}_{\mathrm{Ni}, \mathrm{r}}$-wave, selective IEx (experiment).[24] VPC

(Vinyl- Pyridine-Carboxylic) is a ampholyte resin (Russia).

A lot of such simple binary IEx cases (with a one $i$-component-diffusant) have been studied [20-22] since $60^{\text {th }}$. For the nonselective IEx resin the one component $X_{\mathrm{Ni}, \mathrm{r}^{-}}$ concentration wave (Fig.2a,left) propagates to the (ro),r-Center with the rather smooth and simple spherical $\mathrm{X}_{\mathrm{Ni}, \mathrm{r}}$-profile.

The MMT IEx kinetics process in the nonselective center-symmetrical ro,r-matrices of the IEx resins is much more interesting for the theoretical study due to the propagation and interference of the multicomponent $X_{i r o, r}$-concentration waves [3,7,8,25-28].

The multi-Diffusion $\left\{\mathrm{D}_{i}\right\}$ nonselective IEx system of the MMT kinetics process with the interferences of the multicomponent $\mathrm{X}_{i \mathrm{~L}, \mathrm{ro}, \mathrm{r}}$-concentration waves (propagating in the IEx r,ro-matrices) is represented by the ternary Diffusion $\left\{\mathrm{D}_{i}, i={ }_{1} \mathrm{~A},{ }_{2} \mathrm{~B},{ }_{3} \mathrm{C}\right\}$ IEx kinetics: $\left(\mathrm{R}_{1}^{-} \mathrm{A}^{+}\right)_{\text {resin }} /\left({ }_{2} \mathrm{~B}^{+} ;{ }_{3} \mathrm{C}^{+}\right)_{\text {solution }}[7,8]$.

In a number of the previous investigations[25-28,33] of the ternary $\left\{\mathrm{D}_{i=\mathrm{A}, \mathrm{B}, \mathrm{C}\}-}\right.$ Diffusion IEx kinetics there were marked especially the unusual and non-monotonous behavior of the kinetic $F_{B}(T)$-curve with the kinetic maximum $F_{B}{ }^{m a x}\left(T_{m}\right)$, where $T_{m}$ is the corresponding time moment.

The examples of the such unusual, non-monotonous behavior of the kinetic $F_{B}(T)$ curves (i.e. including the kinetic $\mathrm{F}_{\mathrm{B}}{ }^{\text {max }}$-maximum) are demonstrated in S.5.1 via the author's visual method used: by the computed «coupled figures» (Figs. 3a,b). Such method was used in publications $[3,7,8,32]$ with the pair of figures arranged «in line \&abreast» (Figs. 3a,b): $\left\{\right.$ left- $\left.\mathrm{X}_{i \mathrm{r}, \mathrm{ro}} ; \mathrm{F}_{i \mathrm{r}, \mathrm{ro}}(\mathrm{T})-r i g h t\right\}$. The calculated investigation was fulfilled for the discrete $\mathrm{T}_{\mathrm{r}, \mathrm{ro}}{ }^{\mathrm{S}}$-time series $\left(\mathrm{s}=1,2,3 ; \mathrm{T}_{\mathrm{r}, \mathrm{ro}}{ }^{1}\right.$,top $-\mathrm{T}_{\mathrm{r}, \mathrm{ro}}{ }^{3}, \mathrm{~d}$ own $)$ on the computerized «coupled» $\left\{\right.$ left- $\mathrm{X}_{i}, \& \mathrm{Fi}$, right $\}$, Figs. $3 \mathrm{a}(\mathrm{r}), \mathrm{b}(\mathrm{ro})$.

In the «coupled» Figs. 3a(r),b(ro) it is indicated visually below that the interference (i.e.»displacement») between the two invading $\mathrm{X}_{\mathrm{B}}, \mathrm{X}_{\mathrm{C}}$-concentration waves is the theoretically established cause for the non-monotonous behavior of the kinetic $F_{B}(T)$-curve mentioned (i.e. with the $F_{B}{ }^{m a x}\left(T_{m}\right)$-availability). Such Displacement effect with the the kinetic maximum $\left(\mathrm{F}_{\mathrm{B}}{ }^{\text {max }}\left(\mathrm{T}_{\mathrm{m}}\right)\right)$ is called here the «New Displacement Effect» $(\mathrm{NDE})[3,7,8]$. 
The additional study with the non-monotonous $\mathrm{F}_{\mathrm{B}}(\mathrm{T})$-curves behavior in a dependence of the various $D_{A, B}{ }^{1-3}$-diffusivities values (i.e. when $D_{A} ; D_{B}>>D_{C}$ ) is presented (S.5.2, below) by Figs. 4a,b ; 5a,b together with the IEx kinetics $\mathrm{F}_{i}(\mathrm{~T})$-curves, for the $i={ }_{1} \mathrm{~A},{ }_{2} \mathrm{~B},{ }_{3} \mathrm{C}$-components.

The analysis of the results in the previous mentioned articles[25-28,33] concerning the unusual non-monotonous behavior of the kinetic $F_{B}(T)$-curve with the $F_{B}{ }^{\max }\left(T_{m}\right)$ for the ternary IEx kinetics (mentioned above) is presented here in (S.5.2).

The detailed author's review is published $[3,7,8]$ of the investigations presented in the articles [25-28,33] mentioned. The main advantage of the theoretical approach presented here (with the $\mathrm{W}^{+}$-concept including the partial differential mass balance n-Eqs (3.A) for the IEx, MMT) is that it shows the NDEffect in obvious, straightway via the $\mathrm{X}_{i^{-}}$ concentration waves presentations (here Figs.3, left), see also [8]).

Besides the computerized simulation with the wave $\mathrm{W}^{+}$-concept shows that the NDEffect is the only real reason for the non-monotonic behavior of the kinetic $F_{B}$-curve. The «coupled» Figs.3a(r),b(ro) with the inclusion of the corresponding explanations below confirm the last statement.

There is proved (according to the main "coupled" Figs. 3a(r),b(ro), below) that the origin for the non-monotonous behavior of the kinetic $F_{B}(T)$-curve is explained visually by the demonstration of the NDE-effect due to the displacement interference of the two invading $\mathrm{X}_{\mathrm{B}}, \mathrm{X}_{\mathrm{C}}$-concentration waves into the nonselective IEx r,ro-matrices (see left- $\mathrm{X}_{i}$, Figs. $3 a(r), b(r o)) \cdot[3,7,8]$ The visual obvious illustration of the NDE-effect with its influence to the non-monotonous $\mathrm{F}_{\mathrm{B}}(\mathrm{T})$-curve behavior is explained and presented visually via the method of the two «coupled pictures», namely: $\left\{\right.$ wave- $\mathrm{X}_{i} \mid \mathrm{F}_{i}$-kinetic curves $\}$ (Figs. 3a,b). The "coupled pictures" are arranged visually «in line\&abreast» as in Figs. 3a(r),b(ro) (S.5.1).

The main interesting result of the displacement interference of the two invading $\mathrm{X}_{\mathrm{B}}, \mathrm{X}_{\mathrm{C}}$-concentration waves is called here as the «New Displacement Effect»[7,8] (i.e. shortly NDE) in the nonselective IEx resins (for the r-bead, or ro-fiber matrices). In the result of the computerized modeling the NDE effect is demonstrated visually (by the computed «coupled» Figs. 3a(r), b(ro)). The displacement interference between the two invading $\mathrm{X}_{B, C}$-concentration waves $\left(\right.$ left- $\mathrm{X}_{B, C} ;$; Fig3a,b) when the slow $\mathrm{X}_{\mathrm{C}}$-concentration wave displaces the fast $\mathrm{X}_{\mathrm{B}^{-}}$concentration wave leads to the accumulation of the $\mathrm{B}$-component content $\left(\mathrm{F}_{B}\right.$-right,;Fig3a,b) .

The visual computed "coupled" Figs. $3 \mathrm{a}(r), \mathrm{b}(r o),\left(\right.$ left- $\left.\mathrm{X}_{\text {ir, ro }}\left(\mathrm{T}^{\mathrm{S}}\right)\right)$ exhibit the NDE effect during the displacement interference of the $\mathrm{X}_{\mathrm{B}}, \mathrm{X}_{\mathrm{C}}$-concentration waves by the author's method of the two combined «coupled picture» (arranged «in line \& abreast»). $[3,7,8]$ The coupled Figs. $3 a(r), b($ ro $)$ i.e. $\left\{\right.$ left- $\left.\mathrm{X}_{i \mathrm{r}, \mathrm{ro}}\left(\mathrm{T}^{\mathrm{S}}\right) \mid \mathrm{F}_{i \mathrm{r}, \mathrm{ro}}(\mathrm{T})-r i g h t\right\}$ shows visually the B-component $\mathrm{F}_{B}$-accumulation[3,7,8].

The original applied "coupled pictures" method (presented here obviously in the main Figs. 3a(r),b(ro)) for the visual demonstration of the NDE effect in the nonselective ternary IEx kinetics $\mathrm{R}^{-}\left({ }_{1} \mathrm{~A}^{+}\right)$resin $/\left({ }_{2} \mathrm{~B}^{+} ;{ }_{3} \mathrm{C}^{+}\right)_{\text {solution }}$ is described in details in S.5.1.

\subsection{New Displacement Effect (NDE) in the nonselective ternary IEx kinetics via the author's «coupled Figures» method}

There is considered in the manuscript $(\mathrm{S} .5,6)$ the results of the theoretical investigation obtained by the computerized simulation of the diffusion ternary MMT, IEx kinetics with the various $\mathrm{D}_{i}$-diffusivities $\left\{\mathrm{D}_{i}=\mathrm{D}_{\mathrm{A}}, \mathrm{D}_{\mathrm{B}}, \mathrm{D}_{\mathrm{C}}\right\}$ in the nonselective IEx resin $[3,7,8,32]$.

The MMT, IEx kinetic process here has been modeled $[3,7,8]$ as the particular case of the generalized MMT, NC kinetics process in the bi-functional NC matrices (which are considered previously [1-5]). The important key wave $\mathrm{W}^{+}$-concept is applicable also effec- 
tively for the particular case of the considered nonselective $\left\{\mathrm{D}_{i}\right\}$-multi-Diffusion IEx ternary kinetics: $\left(\mathrm{R}_{1}^{-} \mathrm{A}^{+}\right)_{\text {resin }} /\left({ }_{2} \mathrm{~B}^{+}{ }_{3} \mathrm{C}^{+}\right)_{\text {solution. }}$. The corresponding propagation and interference

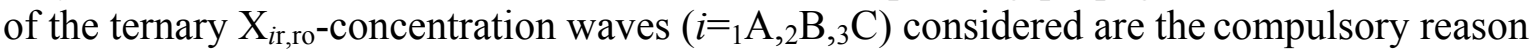
for the mentioned noval NDE-effect inside the nonselective IEx r,ro-matrices[3,7,8].

For the nonselective (i.e. mono-functional in the destinction to the bi-functional NC) IEx, MMT kinetics system considered here the results of the MMT simulation are obtained by the same method of the numerical computerized solution of the partial differential mass balance n-Eqs.(3.A), however without the Selectivity terms, (see S.3). In this case there are included into the consideration only the multi-Diffusion $\left\{\mathrm{D}_{i}\right\}$-terms in the $\mathrm{n}$ Eqs.(3.A) for each $i$-component $\left(i={ }_{1} \mathrm{~A},{ }_{2} \mathrm{~B},{ }_{3} \mathrm{C}\right)$. It is essential that in this case of the nonselective IEx kinetics the «coupling» effect of the electric $\Phi$-field in the fundamental NernstPlank relations (3.1) is included also into the consideration with the interference (3.5) of the $\mathrm{X}_{i r, \mathrm{ro}, \mathrm{L}}$-concentration waves in the IEx resin.

For the study of the New Displacement Effect (NDE) considered ( S.5.1-5.2) the original method of the presentation of the computerized simulation results has been used with the visual demonstration of the combined «coupled pictures» which are arranged by the author «in line \& abreast»: $\left\{\right.$ left- $\mathrm{X}_{i} \mid \mathrm{F}_{i}$-right $\}$ during $\mathrm{T}_{\mathrm{r}, \mathrm{ro}}^{\mathrm{S}}$-time series as in the main Figs. $3 \mathrm{a}\left(\mathrm{T}_{\mathrm{r}}{ }^{1-3}\right) ; \mathrm{b}\left(\mathrm{T}_{\mathrm{ro}}{ }^{1-3}\right) .[3,7,8]$

Hereinafter for short in the nonselective IEx kinetics process the following explanations of the NDE-effect via the author's «coupled pictures» method will be given only for the IEx r-matrix (Figs. 3a(r); $\mathrm{T}_{\mathrm{r}}{ }^{1-3}$-time series).

Naturally that the explanations via the «coupled pictures» for the ro-matrix (Figs.3b(ro); $\mathrm{T}_{\mathrm{ro}}{ }^{1-3}$-time series) are identical to the $\mathrm{r}$-matrix case. However it will be shown further (by comparison) that the NDEffect for the ro-matrix is essentially smaller (Figs.3b(ro), $\mathrm{T}_{\text {ro }}{ }^{1-3}$-series).

In other words the «coupled pictures» (for $\mathrm{T}_{\mathrm{r}}^{1-3}$-time series, IEx r-matrix) are presented by the two pictures arranged by the author «in line \& abreast» (viz. left \& right), i.e. $\left\{\right.$ left- $\mathrm{X}_{i r}\left(\mathrm{~T}^{\mathrm{S}}\right) \mid \mathrm{F}_{\text {ir }}(\mathrm{T})$-right $\}$ in the computed Figs.3a(r), (top, $\left.\mathrm{T}_{\mathrm{r}}{ }^{1}-d o w n, \mathrm{~T}_{\mathrm{r}}^{3}\right)$. Coupled pictures $\left\{\mathrm{X}_{i r}\left(\mathrm{~T}^{\mathrm{S}}\right) \mid \mathrm{F}_{\text {ir }}(\mathrm{T})\right\}$ represent the results of the computerized MMT, nonselective IEx kinetics simulation.

Thus the two separate functional $\left\{\mathrm{X}_{i r}(\mathrm{~T}) ; \mathrm{F}_{i r}(\mathrm{~T})\right\}$-dependences are designedly incorporated by the author «in line \& abreast» into the computed coupled pictures: \{left$\mathrm{X}_{i r}\left(\mathrm{~T}^{\mathrm{S}}\right) \mid \mathrm{F}_{i r}(\mathrm{~T})$-right $\}$ in Figs. $3 \mathrm{a}(r)$ for the nonselective IEx r-matrix.

In the process of the modeling the $\mathrm{X}_{i r, r o}\left(\mathrm{~T}^{\mathrm{S}}\right)$-concentration waves-distributions in Figs. $3 \mathrm{a}(r)$; $\left(\right.$ left- $\mathrm{X}_{i r}\left(\mathrm{~T}^{\mathrm{S}}\right)$, where $\left.\mathrm{T}^{\mathrm{S}}=\mathrm{T}_{r}{ }^{1-3}\right)$ have been computed at the instant time moments, $\mathrm{T}^{\mathrm{S}}=\mathrm{T}_{r}, 2,3(\mathbf{a}$,left $)$. The computed example of the $\mathrm{X}_{i r}$-concentration waves $\left(\right.$ left- $\left.\mathrm{X}_{i r}\right)$ for the «coupled pictures» are represented for three moments in the time series: «top, $\mathrm{T}_{\mathrm{r}}^{1}$ down, $\mathrm{T}_{\mathrm{r}}^{3}$ 》 in $\left(\right.$ left- $\left.\mathrm{X}_{i r}\right)$, Figs. $3 \mathbf{a}(r)$, left side. Thus three $\mathrm{X}_{i r}\left(\mathrm{~T}^{\mathrm{S}}\right)$-concentration wavesprofiles are shown for the three discrete $\mathrm{T}_{r}{ }^{1-3}$-moments: top, $\mathrm{T}_{r}{ }^{1}-$ down, $\mathrm{T}_{r}{ }^{3}$ (left-X $\mathrm{X}_{i r}$, Figs. $3 a(r))$.

For the same $\mathrm{T}_{\mathrm{r}}^{\mathrm{S}}$-time series, Figs. $3 \mathrm{a}\left(\mathrm{F}_{i r}(\mathrm{~T})\right.$-right $)$ show correspondingly the kinetic $\mathrm{F}_{i r}$-curves together for the $\mathrm{T}_{r}^{1,2,3}$-moments which are marked by the three s-dots $(0)$ placed correspondingly on the three $\mathrm{F}_{\mathrm{B} r}(\mathrm{~T})$ curves in correspondence with the $\mathrm{T}_{r}{ }^{\mathrm{S}}$-time: top, $\mathrm{T}_{r}{ }^{1}-$ down, $\mathrm{T}_{r}{ }^{3}$ in Figs. $3 \mathrm{a}\left(\mathrm{F}_{i r}(\mathrm{~T})\right.$-right $)$.

Thereby the important principal main position: «synchronization» of the left and right sides of the «coupled pictures» is applied by author with the visual consideration and analyses of the computed «coupled pictures» presenting as $\left\{\right.$ left- $\mathrm{X}_{i} \mid \mathrm{F}_{i}$-right $\}$ in Figs. 3a (for the $\mathrm{T}_{r}^{1-3}$ time series: top, $\mathrm{T}_{r}^{1}-$ down, $\mathrm{T}_{r}{ }^{3}$ ).

The $\mathrm{T}_{r, r o} \mathrm{~S}$-time synchronization is realized between two «in line» sides \{left$\left.\mathrm{X}_{i r} ; \mathrm{T}_{r}{ }_{r}^{\mathrm{S}}\right) \mid \mathrm{F}_{i r}(\mathrm{~T})$-right $\}$ of the Figs.3a(r), $\mathrm{b}($ ro $)$ for the both functional dependencies («in line 
$\&$ abreast») during the $\mathrm{T}_{r}{ }_{r}^{\mathrm{S}}$-time family in Figs.3a $(r)$. For this purpose the discrete instant $\mathrm{T}_{r}^{1-3}$-time moments considered are marked by the three $\mathrm{T}_{r}^{\mathrm{S}}$-verticals which have the black --base $\left(\mathrm{T}_{r}{ }^{\mathrm{S}}, \mathrm{s}=1,2,3\right)$ on $\mathrm{T}_{r}$-abscissa in Figs. 3a $\left(\mathrm{F}_{\mathrm{B} r}\right.$-right, three $\mathrm{T}_{r}{ }^{\mathrm{S}}$-verticals: top, $\mathrm{T}_{r}{ }^{1}$ down, $\mathrm{T}_{r}^{3}$ ). The each $\mathrm{T}_{r}{ }^{\mathrm{S}}$-base $(\bullet)$ of the $\mathrm{T}_{r}{ }^{\mathrm{S}}$-verticals (Figs3a, $\mathrm{F}_{\mathrm{B} r}(\mathrm{~T})$-right) is terminated by the white s-dot $(\mathrm{O}, u p)$ on the three $\mathrm{F}_{\mathrm{B} r}(\mathrm{~T})$-curves $\left(\mathrm{Figs} .3 \mathrm{a}(r): \mathrm{F}_{\mathrm{B} r}(\mathrm{~T})\right.$-right; $\mathrm{T}_{r}^{\mathrm{S}}$-verticals: top, $\mathrm{T}_{r}{ }^{1}$-down, $\mathrm{T}_{r}^{3}$ ).

In the course of T-time (from top, $\mathrm{T}_{r}{ }^{1}$ till down, $\mathrm{T}_{r}{ }^{3}$, in Figs. $3 \mathrm{a}(r)$ the white 0 -dot «transfers» (i.e. slides visually) along the $\mathrm{F}_{\mathrm{B} r}(\mathrm{~T})$-functional curve (in the $\mathrm{T}_{r}{ }^{1-3}$ series: i.e. along $\mathrm{F}_{\mathrm{B} r}(\mathrm{~T})$-curve in Figs. $3 \mathrm{a}, \mathrm{T}_{r}{ }^{1-3} ; \mathrm{F}_{\mathrm{B} r}(\mathrm{~T})$-right $)$.

Simultaneously with the time $\left(\mathrm{T}_{r}^{\mathrm{S}}\right)$ «sliding» of the white $\circ$-dot $(\mathrm{s}=1,2,3)$, demonstrating the corresponding ${ }_{2} \mathrm{~B}_{r}{ }^{\mathrm{S}}$-filling (Figs. $3 \mathrm{a}(r), \mathrm{T}_{r}{ }^{1-3}, \mathrm{~F}_{\mathrm{B} r}$-right) there are demonstrated the cor-responding $\mathrm{X}_{i r}\left(i={ }_{1} \mathrm{~A},{ }_{2} \mathrm{~B},{ }_{3} \mathrm{C}\right)$-concentration waves-profiles (left- $\mathrm{X}_{i r}$, Figs.3a) during the $\mathrm{T}_{r}^{1-3}$-series (left): from $\mathrm{T}_{r}^{1}$ moment (top) till $\mathrm{T}_{r}^{3}$ one (down).

The maximum $\mathrm{F}_{\mathrm{B} r}{ }^{\max }\left(\mathrm{T}_{\mathrm{m}}\right)$-value on the any non-monotonous $\mathrm{F}_{\mathrm{B} r}(\mathrm{~T})$-curve is marked by the $\mathrm{T}_{\mathrm{m} r}$-vertical (dashed) with the two (up\&down) «colored» $\bullet$-dots notation (Figs. 3a, $\mathrm{F}_{\mathrm{B} r}^{\max }\left(\bullet-\mathrm{T}_{\mathrm{m} r}\right)$, right).

The details of the considered NDE effect (i.e. the displacement of the ${ }_{2} \mathrm{~B}$ concentration wave by the propagating ${ }_{3} \mathrm{C}$-wave via its «incursion»: $\mathrm{T}_{r}{ }^{1-3}$ left) are represented ( $\left(\right.$ left $-\mathrm{X}_{i \mathrm{r}}\left(\mathrm{T}^{\mathrm{S}}\right)$, Figs.3a) via the $\mathrm{X}_{i r}$-concentration ${ }_{2} \mathrm{~B},{ }_{3} \mathrm{C}$-waves behavior displaying at the $\mathrm{T}_{r}^{\mathrm{S}}$-time moments (left-X $\mathrm{X}_{i r}$, Figs. 3a, $\mathrm{T}_{r}^{1,2,3}$ ). The compelling reason for the NDEffect is specified mainly by the displacement interference of the two - slow ${ }_{3} C$ and fast ${ }_{2} \mathrm{~B}$-waves during their diffusion to the r,ro-Centers (where $r, r o=0$ ), (left side, in Figs. $3 \mathrm{a}(r) ; \mathrm{b}(\mathrm{ro}))$.

It is proved (just below) that during the propagation of the $\mathrm{X}_{i r}$-concentration waves the slow $\mathrm{X}_{\mathrm{Cr}}$-wave displaces the fast $\mathrm{X}_{\mathrm{Br}}$-wave (for the given $\mathrm{D}_{\mathrm{B}}>>\mathrm{D}_{\mathrm{C}}$ relation: left- $\mathrm{X}_{i r}$, Figs. $\left.3 \mathrm{a}(r), \mathrm{T}_{r}{ }^{1-3}\right)$. The NDE is conditioned due to the frontal ${ }_{3} \mathrm{C}$-wave (dotted) incursion (left- $\mathrm{X}_{i r}, \mathrm{~T}_{r}{ }^{1-3}$ ) into the $\mathrm{X}_{\mathrm{B} r}$-wave region (during the $\mathrm{T}_{r}{ }^{1-3}$ time series (left- $\mathrm{X}_{i r}$, Figs.3a $(r)$ ).

This incursion of the slow $\mathrm{X}_{\mathrm{Cr}}$-wave (left- $\mathrm{X}_{\mathrm{Cr}}$, dotted, Figs. $3 \mathrm{a}(r)$ ) is the reason for the NDE effect with the displacement of the fast $\mathrm{X}_{\mathrm{B} r}$-wave $\left(\right.$ left- $\mathrm{X}_{\mathrm{B} r}$, Figs. 3a $\left.(r)\right)$. The frontal $\mathrm{X}_{\mathrm{Cr}}$-wave incursion occurs at the $r_{S}$-positions $\left(\mathrm{r}_{1,2,3}\right.$; left, where $\left.\mathrm{X}_{\mathrm{Cr}}=0\right)$ which are marked by the brown $\bullet$-dot (base on $r$-abscissa), (left- $\mathrm{X}_{\text {ir }}$ ), in Figs. $3 \mathrm{a} ; \mathrm{T}_{r}^{1,2,3}$ ).

The computed (left- $\mathrm{X}_{i r}$ ),Figs.3a demonstrate the moving $\mathrm{V}_{\mathrm{S}}$-verticals with the $\mathrm{r}_{\mathrm{S}}$ positions $(\mathrm{s}=1,2,3)$ on $r$-abscissa (where the each $r_{\mathrm{S}}$-base is denoted by the brown $\bullet$-dot). The each $\mathrm{V}_{\mathrm{S}}$-vertical $\left(\mathrm{s}=1,2,3\right.$; left- $\mathrm{X}_{i r}$, Figs. $\left.3 \mathrm{a}(r)\right)$ is terminated by the corresponding «white and black» up arrows: (, $\mathrm{c})$; $(\mathbf{\imath}, \mathrm{b})$ which indicate the ${ }_{2} \mathrm{~B}_{r}$-accumulation in the oval up, along $\mathrm{V}_{\mathrm{S}}$-vertical $(\mathrm{s}=1,2,3)$ on the $\mathrm{X}_{\mathrm{B} r}$-concentration wave, (left- $\mathrm{X}_{i r}, \mathrm{~T}_{r}^{1-3}$; Figs.3a $(r)$ ).

The NDE location of the ${ }_{2} \mathrm{~B}_{r}$-accumulation (in the oval Dis indicated by the «up arrows» ( $仓$,a) of the mobile $\mathrm{V}_{\mathrm{S}}\left(\mathrm{T}_{r}^{\mathrm{S}}\right)$-verticals with $\mathrm{r}_{\mathrm{S}}$, $\bullet$-base (moving along $r$-abscissa) in the computed - (left- $\left.\mathrm{X}_{\mathrm{B} r}, \mathrm{~T}_{r}^{1-3}\right)$, Figs.3a.

The $\mathrm{r}_{\mathrm{S}}(\mathrm{a})$; $\operatorname{ro}_{\mathrm{S}}(\mathrm{b})$-positions $(\bullet)$ together with the up arrows $(\uparrow, \mathrm{\imath}) ;(\boldsymbol{\boldsymbol { \imath }}, \mathrm{b})$ exactly on the $\mathrm{V}_{\mathrm{S}}$-vertical $(\mathrm{s}=1,2,3)$ prove the existence of the NDE effect (in the ovals) which is increased in the course of $\mathrm{T}_{r, r o}$-times (left- $\mathrm{X}_{i r, r o}$, Figs. 3a,b; from $\mathrm{T}_{r, r o}{ }^{1}$ till $\mathrm{T}_{r}^{3}$ ).

The coincidence mentioned between the two various characteristics: a) the $r_{\mathrm{S}^{-}}$ positions on $r$-abscissa (marked by $\bullet$-dots) for the frontal $\mathrm{X}_{3 \mathrm{C}}$-wave boundary $\left(\mathrm{X}_{3 \mathrm{Cr}}=0\right) ; \mathrm{b}$ ) the $r_{\mathrm{S}}$-positions for ${ }_{2} \mathrm{~B}_{r}$-accumulation (in the vals. up) on the $\mathrm{X}_{\mathrm{B} r}$-concentration waves (left- $\mathrm{X}_{i r}, \mathrm{Figs.3 \textrm {a }}(r), \mathrm{T}_{r}{ }^{1-3}$ ) proves the reason for the NDE effect: the slow ${ }_{3} \mathrm{C}_{r}$-wave displaces the fast ${ }_{2} \mathrm{~B}_{r}$-wave due to ${ }_{3} \mathrm{C}_{r}$-wave incursion by its frontal part ( $\bullet$-dots, $\mathrm{r}_{\mathrm{S}}$-positions) into the ${ }_{2} \mathrm{~B}_{r}$-wave (left-X $\mathrm{X}_{i r}$, Figs.3a $\left.(r), \mathrm{T}_{r}{ }^{1-3}\right)$. 
The presented time diapasons: $\mathrm{T}_{r}^{1-3}$ (or $\mathrm{T}_{r o}{ }^{1-3}$ ) cover the region $\left(0<\mathrm{T}_{\mathrm{m} r, \mathrm{~m} r o}<\mathrm{T}_{r, r o}{ }^{3}\right.$ ) around the $\mathrm{T}_{\mathrm{m} r}(0.21)$, or $\mathrm{T}_{\mathrm{m} r o}(0.56)$-values (•-dots in Figs. $3 \mathrm{a}(r), \mathrm{b}(r o), \mathrm{F}_{\mathrm{B} r, r o}$-right).

Thus it means certainly that the reason for the ${ }_{2} \mathrm{~B}_{r}$ - accumulation (in the up 《ovals left, Figs.3a $(r)$ ) is the displacement effect (NDE) for the fast $\mathrm{X}_{\mathrm{Br}}$-concentration wave by the incursion (in the $\bullet$-points: $\left.\mathrm{r}_{1}, \mathrm{r}_{2}, \mathrm{r}_{3}\right)$ of the slow frontal $\mathrm{X}_{3 \mathrm{Cr}}$-concentration wave $\left(\right.$ left- $\mathrm{X}_{\mathrm{B} r}$, Figs $\left.3 \mathrm{a}(r), \mathrm{T}_{r}^{\mathrm{S}}\right)$.

Therewith the computed Figs. $3 \mathrm{a}(r)$ with the «coupled pictures»: \{left $\mathrm{X}_{i r}\left(\mathrm{~T}^{\mathrm{S}}\right) \mid \mathrm{F}_{i r}(\mathrm{~T})$ - right $\}$ are included as the computed frames-«coupled pictures» at the successive $\mathrm{T}_{r}{ }_{r}$-time moments into the author's computed multi-colored SCAnimations ( «SCA.avi» video files) mentioned earlier (in S.2,3) and discussed later (in S.6.2).

The scanning of the "SCA.avi» video files (during the oral presentation) demonstrate the occurrence of the NDE effect with the evidence and distinctiveness. It goes without saying in contrast to the long and laborious explanation cited above. It is especially evident during the multi-colored SCAnimation ( $\langle S C A$.avi») scanning (due to the movable $\mathrm{V}_{\mathrm{S} r, r o}$-verticals with theirs basis $\left(\bullet, r_{S}\right.$-positions) that the $\mathrm{X}_{\mathrm{B} r}(\mathrm{~T})$-wave is displaced by the frontal incursion (in $\bullet-\operatorname{dot}\left(\mathrm{r}_{1,2,3}\right)$, where $\mathrm{X}_{3 \mathrm{C} r, r o}=0$ ) of the slow $\mathrm{X}_{3 \mathrm{Cr}, r o}(\mathrm{~T})$-waves.

The NDE effect includes the influence of the geometrical shapes (r-bead, ro-fiber) of the IEx r,(ro)-matrices during the MMT, IEx kinetics process presented (left-X $\left.\mathrm{X}_{i r, r o}\right)$ in Figs. $3 \mathrm{a}(r), \mathrm{b}(r o)$. For the both r,ro-matrices the location of the NDE effect is indicated by the movable $\mathrm{V}_{\mathrm{S}}\left(\mathrm{T}_{r, r o}{ }^{\mathrm{S}}\right)$-verticals with the basis $\left(\bullet-\mathrm{r}_{\mathrm{S}}, \mathrm{ro}_{\mathrm{S}}\right)$ terminating by up arrows $(\uparrow, \mathrm{a})$;

,b) in (left-X $\mathrm{X}_{i r, \mathrm{ro}}$; Figs. 3a,b). The $\mathrm{V}_{\mathrm{S}}$-verticals with the $\mathrm{r}_{\mathrm{S}}$, ro $_{\mathrm{S}}$-positions $(\bullet)$ together with the up arrows ( $\mathrm{u}, \mathrm{a}) ;(\mathbf{0}, \mathrm{b})$ prove the NDE existence and indicate the NDE effect (left$\mathrm{X}_{i r, r o}$, Figs. $\left.3 \mathrm{a}(r), \mathrm{b}(r o)\right)$.

The physical sense of the $\mathrm{X}_{\mathrm{B} r}$-concentration jump which localized by $\mathrm{V}_{\mathrm{S}}\left(\mathrm{T}_{r}{ }^{\mathrm{S}}\right)$ verticals, in $r_{S(1-3)}$-positions (left- $\mathrm{X}_{\mathrm{B} r}$, Figs.3a, $\mathrm{T}_{r}{ }^{1-3}$ ) including the $\mathrm{F}_{\mathrm{Br}}{ }^{\max }$ peak on the $\mathrm{F}_{\mathrm{B} r}$ curve (Figs. 3a, $\mathrm{F}_{\mathrm{B} r}$-right) for the $\mathrm{r}$-bead should be explained by the steep decrease of the current $r$-volume $\left(\sim r^{2} d r\right)$ for the $X_{\mathrm{B} r}$-wave diffusion through the r-surface $\left(4 \pi r^{2}\right)$. It is obvious that the decrease of the current ro-volume $(\sim \mathrm{ro} * \mathrm{~d}(\mathrm{ro}))$ for the diffusion of the $\mathrm{X}_{\mathrm{B} r o^{-}}$ wave through the ro-surface $(2 \pi \mathrm{ro} * \mathrm{~h})$ is not steep.

Thus for the ro-fiber the ro-surface change $(\sim \mathrm{ro} * \mathrm{~d}(\mathrm{ro}))$ doesn't show the steep decrease (but gradual only). Therefore the $\mathrm{X}_{\mathrm{B} r o}$-accumulation (at $\mathrm{ro}_{1-3}$-positions) for the rofiber is gradual (left in ovals. Figs $3 b$ ). Therefore the $\mathrm{X}_{\mathrm{B} r o^{-}}$-concentration jump is not possible (see the gradual small change in $\mathrm{X}_{\mathrm{B} r o^{-}}$-accumulation (in 0 vals 8 , Figs. $3 \mathrm{~b}$ ) at the $\mathrm{ro}_{1-3^{-}}$ positions $(\bullet)$, series $\mathrm{T}_{r o}{ }^{1-3}$, (left- $\mathrm{X}_{\mathrm{B} r o}$, blue. dashed lines);, Figs. $3 \mathrm{~b}, \mathrm{~F}_{\mathrm{B} r o}{ }^{\max }$ ).

The comparison of the details of the NDE effect for r-bead $\left\{\left(\right.\right.$ left- $\left.X_{i r}\right)$, Figs. 3a\}, and ro-fiber (left-X $\mathrm{X}_{\text {iro }}$, Figs. $3 \mathrm{~b}$ ) represents the difference between the results of the modeling. Figures $3 \mathrm{a}(\mathrm{r}), \mathrm{b}(\mathrm{ro})$ display visually that the displaced $\mathrm{X}_{\mathrm{Br}}$-wave (for r-bead, left Figs. 3a) comes to the $\mathrm{T}_{\mathrm{m} r}$-moment with the $\mathrm{X}_{\mathrm{B} r}$-concentration jump (left- $\mathrm{X}_{\mathrm{B} r}$, in ovals $3 \mathrm{a}$ ), while the $\mathrm{X}_{\mathrm{B} r o}$-wave comes to the $\mathrm{T}_{\mathrm{m} r o}$-moment without the $\mathrm{X}_{\mathrm{B} r o}$-wave jump (left- $\mathrm{X}_{\mathrm{B} r o}$; Figs. 3b) but with the gradual profile.

The corresponding marks («up arrows» $仓$, a ;, $\mathrm{b}$ ) for $\mathrm{X}_{\mathrm{B} r, r o}\left(\mathrm{~T}^{1-3}\right)$-profiles are presented in Figs.3a,b $\left(\right.$ left- $\left.\mathrm{X}_{\mathrm{B} r, r o}\right)$. They demonstrate that the $\mathrm{X}_{\mathrm{B} r o}$-accumulation for the rofiber is not so intensive as for the r-bead: $\mathrm{T}_{\mathrm{m} r}(0.21)<\mathrm{T}_{\mathrm{m} r o}(0.56)$, (see, Figs.3a $(r), \mathrm{b}(r o)$, $\mathrm{F}_{B r, \mathrm{ro}}(\mathrm{T})$-right).

The original presentation with the «in line and abreast», coupled pictures synchronized $\left\{\mathrm{X}_{i r, r o}\left(\mathrm{~T}^{\mathrm{S}}\right)\right.$, left $\mid \mathrm{F}_{i r, r o}(\mathrm{~T})$,right $\}$ (such as in the main Figs. $3 \mathrm{a}(r), \mathrm{b}(r o)$ ) gives the effective and visual interpretation of the results of the computerized MMT kinetics simulation in the course of T-time in Figs. $3 \mathrm{a}(r), \mathrm{b}($ ro $)\{l e f t$; right $\}$. In the meanwhile the computerized 
simulation of the $\mathrm{X}_{i}$-concentration waves behavior (left- $\mathrm{X}_{i r, r o}$, Figs. $\left.3 \mathrm{a}(r), \mathrm{b}(r o)\right)$ shows that the NDE is more intensive for the r-bead: i.e. $\mathrm{T}_{\mathrm{m} r}(\mathrm{a})<\mathrm{T}_{\mathrm{m} r o}(\mathrm{~b})$.

By the visual analysis it is seen that in the fast $X_{\mathrm{B}}$-concentration wave displaced by the incursion of the front of the $\mathrm{X}_{3 \mathrm{C} r}$-wave (left- $\mathrm{X}_{\mathrm{B} r, r o}$; Figs. $3 \mathrm{a}\left(\mathrm{T}_{r}{ }^{1-3}=0.1-0.7\right) ; \mathrm{b}\left(\mathrm{T}_{\mathrm{ro}}{ }^{1-3}=0.5-\right.$ $0.7)$ ) brings the $\mathrm{B}_{r, r o}$-accumulation (left) together with the unusual non-monotonous kinetic integral $\mathrm{F}_{\mathrm{B} r, r o}$-curves behavior (Figs. $3 \mathrm{a}(r), \mathrm{b}(r o), \mathrm{F}_{\mathrm{B} r, r o}$-right).

The author's SCA animations (SCA.avi) scanning shows all the described NDE effects visually \& obviously (and much easier for the perception by the sci. audience).

The local $\mathrm{X}_{\mathrm{B} r, r o}$-concentration accumulation is seen on the left side (left, Figs. $3 \mathrm{a}(r), \mathrm{b}(r o)$. The integral ${ }_{2} \mathrm{~B}_{r, r o}$-accumulation is seen on the right side of the "coupled pictures»: $\left(\mathrm{F}_{i}(\mathrm{~T})\right.$-right $)$ with the maximum $\mathrm{F}_{\mathrm{B} r, r o}{ }^{\max }$-values marked by the colored $\bullet$-dots $\left(\mathrm{T}_{\mathrm{m} r}, \mathrm{~T}_{\mathrm{m} r o}\right)$ in the $\mathrm{T}_{r, r o}{ }^{1-3}$-time series in Figs. $3 \mathrm{a}(r), \mathrm{b}(r o)$.

Thus the NDE effect for the $\mathrm{X}_{\mathrm{Br}}$-concentration wave in the r-bead is the most intensive (Figs. $3 \mathrm{a}(r)$, left). However the total integral NDE effect- $\mathrm{F}^{\max }\left(\mathrm{T}_{\mathrm{m}}\right)$ depends not from $\mathrm{T}_{\mathrm{m} r, r o}$ only but additionally from the duration of the MMT kinetics process. Though the local (Intensity ${ }_{r, r o}$ ) of the NDE is stronger for the r-bead in comparison with the ro-fiber, however the corresponding $\mathrm{T}_{\mathrm{m} r}=0.2$ value is shorter in comparison with $\mathrm{T}_{\mathrm{m} r o}=0.57$-value for the ro-fiber.

(a) r-bead; $\mathrm{T}_{\mathrm{r}}^{\mathrm{S}}$-time family (top, $\mathrm{T}_{\mathrm{r}}{ }^{1}-$ down, $\left.\mathrm{T}_{\mathrm{r}}{ }^{3}\right): \mathrm{T}_{\mathrm{r}}{ }^{1-3}=0.1 ; 0.2 ; 0.7$

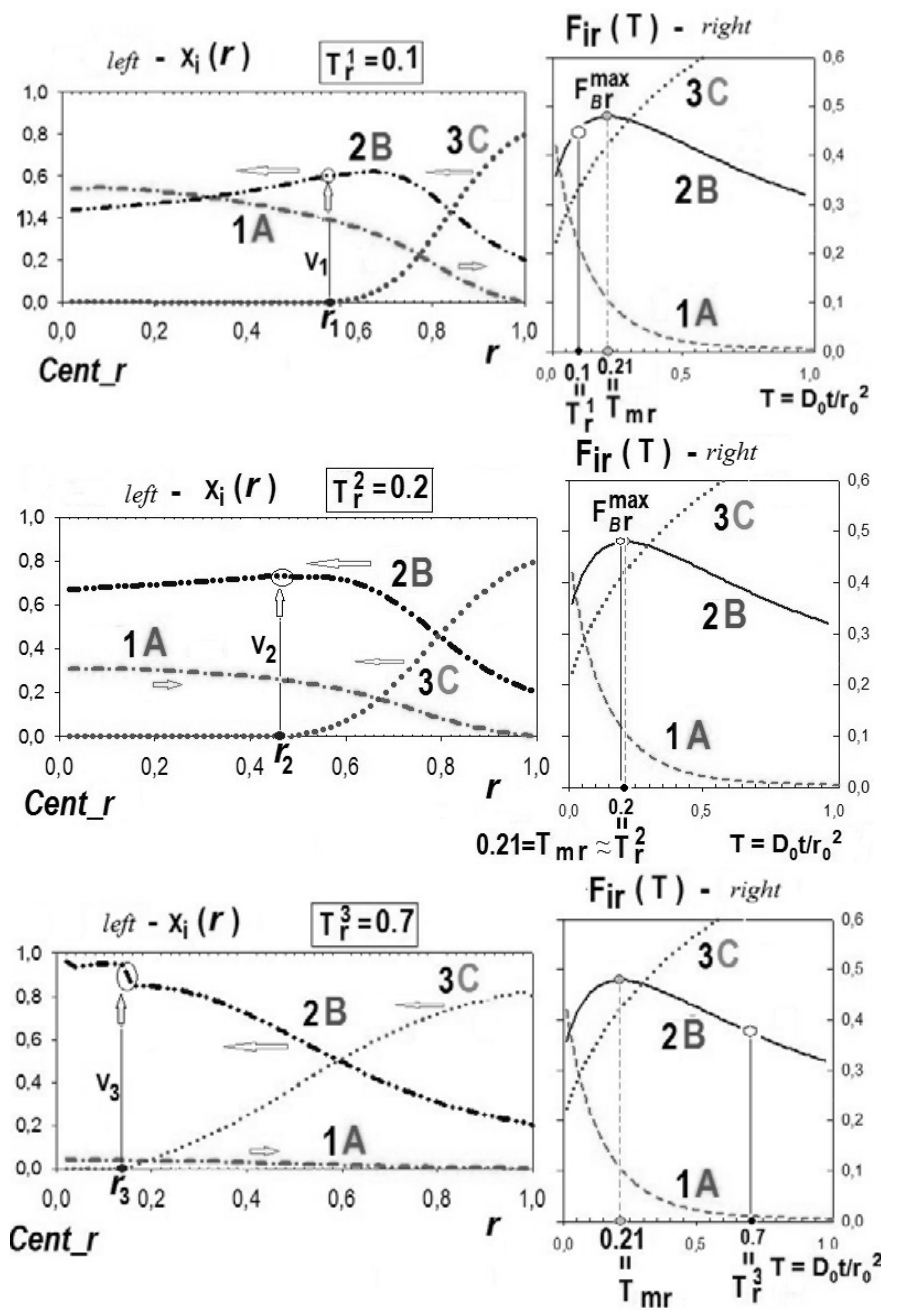

b) ro-fiber; $\mathrm{T}_{\mathrm{ro}}{ }^{\mathrm{S}}$-time family $\left(\right.$ top, $\mathrm{T}_{\mathrm{ro}}{ }^{1}-$ down, $\left.\mathrm{T}_{\mathrm{ro}}{ }^{3}\right): \mathrm{T}_{\mathrm{ro}}{ }^{1-3}=0.5 ; 0.6 ; 0.7$ 

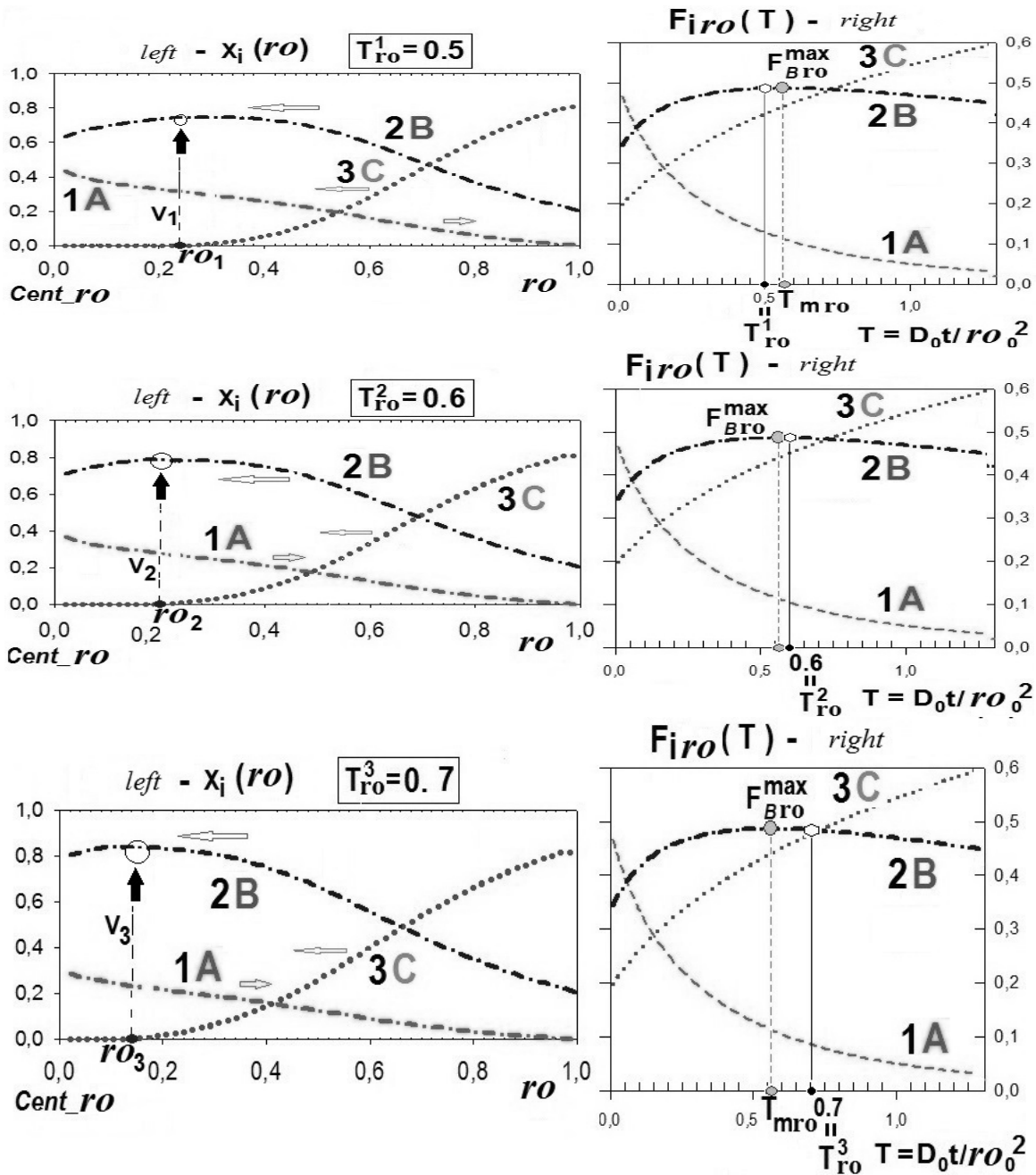

Fig. $37 \mathrm{a}(r) ; \mathrm{b}(r o)$. Nonselective ternary IEx kinetics. New Displacement Effect (NDE), left - $\mathrm{X}_{i r, r o}$. Family (series): $\mathrm{T}_{r}^{1-3}(\mathrm{a}) ; \mathrm{T}_{r o}{ }^{1-3}(\mathrm{~b}) . \mathrm{X}_{i r, r o}$-waves: $\mathrm{X}_{1 \mathrm{~A}}, \mathrm{X}_{2 \mathrm{~B}}-b l u e, \mathrm{X}_{3 \mathrm{C}^{-}}$dotted (left). NDE location: left: $\mathrm{V}_{\mathrm{S}=1-3}$-verticals with «up arrows»: $仓(r) ;(r o) .: r_{\mathrm{S}}, r o_{\mathrm{S}}$-positions,

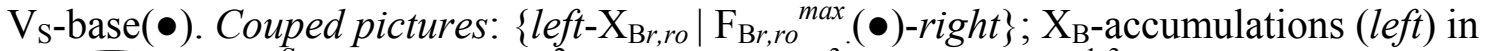
ovals (a) $\mathrm{T}_{r}^{\mathrm{S}} ; \mathrm{T}_{\mathrm{m} r}=0.21 ; \mathrm{T}_{r}^{2}(\bullet)<\mathrm{T}_{\mathrm{m} r}(\bullet)<\mathrm{T}_{r}^{3}(\bullet)$;right: $\mathrm{T}_{r, r o}{ }^{1-3}$-Verticals (right);

(b) $\mathrm{T}_{r o}{ }^{\mathrm{S}} ; \mathrm{T}_{\mathrm{m} r o}=0.56 ; \mathrm{T}_{r o}{ }^{1}(\bullet)<\mathrm{T}_{\mathrm{m} r o}(\bullet)<\mathrm{T}_{r o}{ }^{2}(\bullet) ; \mathrm{F}_{\mathrm{B} r}{ }^{\max } \sim \mathrm{F}_{\mathrm{B} r o}{ }^{\max }(\bullet)$. Horizontal arrowsdirections for $\mathrm{X}_{i r, r o}$-waves movements (to the $r, r o$-Centers).

Thus in the result the integral NDE effect is presented in the $\mathrm{F}_{\mathrm{B} r, r o}(\mathrm{~T})$-curves for the r,ro -matrices as follows: Product $=\mathrm{T}_{\mathrm{m} r, r o *} *$ Intensity $r, r o$. Thefore the integral $\mathrm{F}_{\mathrm{ir}, r o}{ }_{\text {max }}$-values are displayed as almost the same: $\mathrm{F}_{\mathrm{B} r}{ }^{\max }(\mathrm{a}) \sim \mathrm{F}_{\mathrm{B} r o}{ }^{\max }(\mathrm{b})$ in Figs. $3 \mathrm{a}(r), \mathrm{b}(r o)\left(\mathrm{F}_{\mathrm{B} r, r o}(\mathrm{~T})-r i g h t\right)$.

During the MMT IEx simulations the NDE effect is not appeared for the Lmembrane. It means that the interference of the $\mathrm{X}_{\mathrm{CL}}, \mathrm{X}_{\mathrm{BL}}$-concentration waves is not intensive, and besides the $\mathrm{S}_{\mathrm{L}}$-surface for the diffusion $\left(\mathrm{D}_{i}\right)$ of the $\mathrm{X}_{\mathrm{BL}}$ - concentration wave to the other side of the L-membrane during the MMT, IEx process in the L-membrane is permanent $\left(\mathrm{dS}_{\mathrm{L}}=0\right)$. The integral ${ }_{2} \mathrm{~B}_{L}$-accumulation for the L-membrane is absent, and $\mathrm{F}_{\mathrm{B} L}$-curve behavior demonstrates the usual monotonic character (without the $\mathrm{F}_{\mathrm{B} L}{ }^{\mathrm{max}}$ ).

The consideration of the ternary nonselective ternary IEx kinetics: $\left(\mathrm{R}^{-}\right.$ $\left.{ }_{1} \mathrm{~A}^{+}\right)_{\text {res }} /\left({ }_{2} \mathrm{~B}^{+} ;{ }_{3} \mathrm{C}^{+}\right)_{\text {sol }}$ is represented in the articles[3,7,8] by the previously mentioned mathematical approach with the author's «coupled pictures» method (see Figs. $3, \mathrm{a}(r), \mathrm{b}(r o))$. The approach with the application of the propagating $\mathrm{X}_{i}$-concentration waves, 
$\left(\mathrm{W}^{+}\right.$-concept) $[1-5,7,8]$ has the obvious advantage in comparison with the previous results obtained for the ternary IEx kinetics in the earlier publications[26-28,33] mentioned.

The author's approach wih the $\mathrm{W}^{+}$-concept \& «coupled pictures» method (Figs.3a,b, $\left\{\mathrm{X}_{\mathrm{i}}-\right.$ left $\mid \mathrm{F}_{i}$-right $\}$ ) give the possibility to find out and demonstrate (especially via the SCAnimation scanning) the NDEffect for the nonselective IEx in r,ro-matrices of the IEx resins.

This NDE effect appears (under the definite condition: $D_{A}, D_{B}>D_{C}$ ) for the two interfering ${ }_{2} B,{ }_{3} C$-concentration waves («coupled» Figs $3 \mathrm{a}, \mathrm{b}, \mathrm{X}_{i}$, left). This imterference of the $\mathrm{X}_{i}(\mathrm{i}=\mathrm{A}, \mathrm{B}, \mathrm{C})$ waves is the only reason for the anomalous, and non-monotonous behavior of the kinetic $\mathrm{F}_{B}(\mathrm{~T})$-curve (in the «coupled» Figs.3a,b, $\mathrm{F}_{B}$, right). The displacement of the fast incoming $\mathrm{X}_{B}$-concentration wave by the second, (slow) $\mathrm{X}_{\mathrm{C}}$-concentration wave brings the accumulation of the $\mathrm{X}_{B}$ concentration of ${ }_{2} B$-component in the propagating ${ }_{2} B$ wave (see the "coupled" Figs. $3 \mathrm{a}, \mathrm{b}, \mathrm{X}_{\mathrm{B}}, l$ left). In the fast ${ }_{2} B$-wave displaced $\left(\mathrm{X}_{\mathrm{Br}, \mathrm{ro}}\right.$, left, Figs. $3 \mathrm{a}, \mathrm{b}$ ) this $B$-accumulation leads to the unusual non-monotonous $\mathrm{F}_{B \mathrm{r} \text {,ro }}$-curves behavior (the coupled Figs. 3a,b, $\mathrm{F}_{\mathrm{Br}, \mathrm{ro}}{ }^{\max }$, right). The integral $B$-accumulation is increased initially, then it is decreased in the $\mathrm{F}_{\mathrm{Br}, \mathrm{ro}}(\mathrm{T})$-kinetic curves (the coupled Figs. 3a,b; $\mathrm{F}_{\mathrm{Br}, \mathrm{ro}}$, right ) with the availability of the maximum $\mathrm{F}_{\mathrm{Br} \text {,ro }}{ }^{\max }$-values.

The conditions for the appearance of the NDEffect are investigated, and presented in the discussions of the simulation results (Figs. 4,5(a,b)) $[3,7,8,32]$.

The author's approach wih the $\mathrm{W}^{+}$-concept \& «coupled pictures» method (Figs.3a,b, $\left\{\mathrm{X}_{\mathrm{i}}-\right.$ left $\mid \mathrm{F}_{i}$-right $\}$ ) give the possibility to find out and demonstrate (especially via the SCAnimation scanning) the NDEffect for the nonselective IEx in r,ro-matrices of the IEx resins.

This NDE effect appears (under the definite condition: $\mathrm{D}_{\mathrm{A}}, \mathrm{D}_{\mathrm{B}}>\mathrm{D}_{\mathrm{C}}$ ) for the two interfering ${ }_{2} B{ }_{3} C$-concentration waves («coupled» Figs $3 \mathrm{a}, \mathrm{b}, \mathrm{X}_{i}$, left). This imterference of the $\mathrm{X}_{i}(\mathrm{i}=\mathrm{A}, \mathrm{B}, \mathrm{C})$ waves is the only reason for the anomalous, and non-monotonous behavior of the kinetic $\mathrm{F}_{B}(\mathrm{~T})$-curve (in the «coupled» Figs.3a,b, $\mathrm{F}_{B}$, right). The displacement of the fast incoming $\mathrm{X}_{B}$-concentration wave by the second, (slow) $\mathrm{X}_{\mathrm{C}}$-concentration wave brings the accumulation of the $\mathrm{X}_{B}$ concentration of ${ }_{2} B$-component in the propagating ${ }_{2} B$ wave (see the "coupled" Figs. $3 \mathrm{a}, \mathrm{b}, \mathrm{X}_{\mathrm{B}}$, left). In the fast ${ }_{2} B$-wave displaced $\left(\mathrm{X}_{\mathrm{Br}, \mathrm{ro}}\right.$, left, Figs. $3 \mathrm{a}, \mathrm{b}$ ) this $B$-accumulation leads to the unusual non-monotonous $\mathrm{F}_{B \mathrm{r} \text {,ro }}$-curves behavior (the coupled Figs. 3a,b, $\mathrm{F}_{\mathrm{Br}, \mathrm{ro}}{ }^{\max }$, right). The integral $B$-accumulation is increased initially, then it is decreased in the $\mathrm{F}_{\mathrm{Br}, \mathrm{ro}}(\mathrm{T})$-kinetic curves (the coupled Figs. 3a,b; $\mathrm{F}_{\mathrm{Br}, \mathrm{ro}}$, right ) with the availability of the maximum $\mathrm{F}_{\mathrm{Br}, \mathrm{ro}}{ }^{\max }$-values.

The conditions for the appearance of the NDEffect are investigated, and presented in the discussions of the simulation results (Figs. 4,5(a,b)) [3,7,8,32].

The author's consideration of the ternary nonselective IEx kinetics by the mathematical approach in $[3,7,8]$ has the obvious advantage in comparison with the previous results in the publications $[25-28,33]$. The author's results in the modern publication $[3,7,8]$ give the possibility to consider the multicomponent IEx kinetic process not only via the kinetic $\mathrm{F}_{i}$-curves behavior (as it was considered in [25-28,33]), but on the more high and detailed level: via the study of the propagation of the multicomponent interfering $\mathrm{X}_{i^{-}}$ concentration waves behavior in the nonselective IEx matrix of the various shapes: r.romatrixes (as it is demonstrated here in the coupled Figs. 3 a,b, $\left(\mathrm{X}_{\mathrm{Br}, \mathrm{ro}}\right.$, left ) $[3,7,8]$.

The consideration of the ternary nonselective IEx kinetics by the mathematical approach in $[3,7,8]$ has the obvious advantage in comparison with the previous results in the publications [26-28,33]. The author's results in the modern publication $[3,7,8]$ give the possibility to consider the multicomponent IEx kinetic process not only via the kinetic $\mathrm{F}_{i}$ curves behavior as it was in [25-28,33], but on the more high and detailed level: via the study of the propagation of the multicomponent interfering $\mathrm{X}_{i}$-concentration waves beha- 
vior in the nonselective IEx matrix of the various shapes: r.ro-matrixes with the coupled Figs.3a,b, $\mathrm{X}_{\mathrm{Br}, \mathrm{ro}}$, left $)[3,7,8]$.

Besides the wide diapason of the $\mathrm{D}_{i}$-diffusivities for the non-monotonous $\mathrm{F}_{\mathrm{Br}, \mathrm{ro}}$ curve behavior and its association with the NDE effect via the coupled Figs. 3 a,b, $\left\{\mathrm{X}_{\mathrm{Br}, \mathrm{ro}}\right.$, left $\mid \mathrm{F}_{i}$, right $\}$ \} (above) has been determined by the detailed mathematical modeling used in $[3,7,8]$. This conclusion is shown with the evidence due to the original author's presentation of the propagating $\mathrm{X}_{i}$-concentration diffusion waves "together and abreast" with the kinetic $\mathrm{F}_{i \mathrm{r}, \mathrm{ro}}$ - curves in the «coupled pictures»: Figs. $3\left\{\right.$ left, $\mathrm{X}_{i} \mid \mathrm{F}_{i}$, right $\}$.

Figures $3 \mathrm{a}($ up,r), $\mathrm{b}($ down,ro) show the NDEffect inside the IEx r, ro-matrices for the interfering ${ }_{2} B{ }_{3} C$-waves (Figs. 3a,b; left- $\mathrm{X}_{i}$, ) which are «abreast» the integral $\mathrm{F}_{B \mathrm{r} \text {,ro }}(\mathrm{T})$ curves $\left(\mathrm{F}_{i}\right.$-right $)$ in «the coupled pictures»: Figs. $3\left\{\right.$ left- $\mathrm{X}_{i} \mid \mathrm{F}_{i}$-right $\}$.

The author's results obtained here, and in $[3,7,8,32]$ are new and displayed for the first time. The discussion of the computerized simulation for the $\mathrm{X}_{i}$-concentration waves produces the proofs for the interference of the $\mathrm{X}_{i}$-concentration waves with the subsequent origination for the NDE effect (via the «coupled pictures» method, Figs. $3 \mathrm{a}($ up, $\mathrm{r}), \mathrm{b}($ down, ro $)) .[3,7,8]$

In result of the computerized simulation $[3,7,8]$ the propagations of the $\mathrm{X}_{i^{-}}$ concentration waves have been calculated for a number of variants of the ternary nonselective diffusion IEx kinetics. The corresponding kinetic $\mathrm{F}_{i}(\mathrm{~T})$-curves have been calculated simultaneously with the $\mathrm{X}_{i}$-concentration waves during the simulations for all the variants with the wide $\left\{\mathrm{D}_{i}\right\}$-diapason (Figs. 4,5) $[3,7,8]$.

In the investigation the most interesting kinetic $\mathrm{F}_{B \mathrm{r}, \mathrm{ro}}(\mathrm{T})$ - curves have been obtained $[3,7,8]$ with the unusual non-monotonous behavior (Figs. 3a(r),b(ro), right; Figs $4,5 \mathrm{a}, \mathrm{b})$. In this non-standard cases the kinetic maximum $-\mathrm{F}_{B \mathrm{r} \text {,ro }} \max ^{\max }$ is available for the kinetic $\mathrm{F}_{B \mathrm{r}, \mathrm{ro}}(\mathrm{T})$ - curves for the r-beads, and ro-fibers (Figs.3a(r),b(ro), $\mathrm{F}_{i}$, right; Figs 4,5a,b). Such variants of the nonselective ternary IEX kinetics were calculated $[3,7,8]$ on the basis of the author's computerized NC Model (but without the property of Selectivity, I).

The results obtained recently $[3,7,8]$ allow to make more precise conclusions (than previously), and to come definitely to the real reasons for the unusual, non-monotonic behavior of the kinetic $\mathrm{F}_{B \text { r,ro }}(\mathrm{T})$-curves with the maximum $\mathrm{F}_{B \mathrm{r} \text {,ro }}{ }_{\max }$-values availability.

The author's results here and in the modern author's publications $[3,7,8]$ give the possibility to consider the IEx, MMT kinetic process not only via the kinetic $\mathrm{F}_{i}$-curves behavior (as it was in the previous other articles [25-28,33]) but on the more high and detailed level based on the $\mathrm{W}^{+}$-concept: the computerized simulation study of the propagation of the multicomponent interfering $\mathrm{X}_{i=1,2,3}$-concentration waves in the nonselective IEx r,ro-matrices.

The corresponding NDE locations are presented in the $\mathrm{X}_{\mathrm{B} r, r o}$-waves by the movable $\mathrm{V}_{\mathrm{S}}$-verticals (left) with the $\mathrm{r}_{\mathrm{S}}$, $\mathrm{ro}_{\mathrm{S}}$-distances $\left(r_{1}=0.57, r_{2}=0.48, r_{3}=0.15\right)$ and $\left(r_{1}=0.24\right.$; $\left.\mathrm{ro}_{2}=0.2 ; \mathrm{ro}_{3}=0.15\right)($ left $-\mathrm{X} \mathrm{Br}, r o)$ in Figs.3a $(r), \mathrm{b}(r o)$, correspondingly.

The time family-series $\left(\mathrm{T}_{r, r o}{ }^{1-3}\right)$ of the «coupled pictures» $\left\{\right.$ left- $\mathrm{X}_{i r, r o}\left(\mathrm{~T}^{\mathrm{S}}\right) \mid \mathrm{F}_{i r, r o}(\mathrm{~T})-$ right $\}$ in Figs. $3 \mathrm{a}(r), \mathrm{b}($ ro $)$ represent the small fragment (three frames -"coupled pictures") of the author's multi-colored SCAnimations (SCA.avi video files) prepared for the visual interpretation of the computerized simulations presented by the author in a number of the oral computer presentations (including «IEx 2004-2012» conferences [18,19,32], see also S.6.).

There is obtained the considerable NDE effect for the fast $\mathrm{X}_{B \mathrm{r}, \mathrm{ro}}$-concentration waves (left- $\mathrm{X}_{\mathrm{B} r, r o}$, Figs.3a(r), $\left.\mathrm{b}(r o)\right)$ «in line and abreast» for the given $\left\{\mathrm{D}_{i}\right\}$-Diffusivities relations $\left(\mathrm{D}_{B}=0.2, \mathrm{D}_{\mathrm{A}}=0.2>>\mathrm{Dc}=0.01\right.$, Figs.3a(r),b(ro). The various diffusivities relations are used in the computerized simulation with the simultaneous integral ${ }_{2} \mathrm{~B}$-accumulation peak- $\mathrm{F}_{\mathrm{Br},{ }^{2}}{ }^{\max }$ (Figs.3a,b, $\mathrm{F}_{\mathrm{B} r, r o}$-right).[3,7,8] The NDE effect takes place for the fast $\mathrm{X}_{\mathrm{B} r, r 0^{-}}$ 
concentration waves (left- $\left.\mathrm{X}_{\mathrm{B} r, r o}\right)$ in Figs. $3 \mathrm{a}(r), \mathrm{b}(r o)$ at the definite conditions (i.e. for the definite $\left\{\mathrm{D}_{i}\right\}$-Diffusivities relations (see the next S.5.2).

\subsection{Non-monotonous behaviour of the kinetic $F_{B}(T)$-curve for the MMT in the nonselective IEx for the various $\left\{D_{B}, D_{A}\right\}$-Diffusivity values}

Among two $\mathrm{X}_{2 \mathrm{~B}}, \mathrm{X}_{3 \mathrm{C}}$-concentration waves invading into the nonselective IEx resin the $\mathrm{X}_{3 \mathrm{C}}$-concentration wave (displacer) moves much slower (in this case $\mathrm{D}_{\mathrm{B}}>>\mathrm{D}_{\mathrm{C}}$ ) than the fast $\mathrm{X}_{2 \mathrm{~B}^{-}}$concentration wave. However the incursion of the frontal «head» (with zero con-

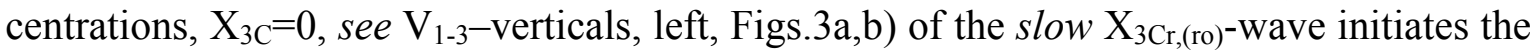
$\mathrm{NDE}$ effect in the $r_{1-3} ; r o_{1-3}$-positions of the $\mathrm{X}_{3 \mathrm{C}}$-wave incursion. The locations $\left(r_{\mathrm{S}} ; \mathrm{ros}_{\mathrm{S}}\right)$ of the $\mathrm{X}_{3 \mathrm{C}}$-frontal wave incursion (see the $\mathrm{V}_{1-3}$-verticals, $\mathrm{a}(r)$; $\mathrm{b}($ ro $)$ ) in Figs.3a $(r) ; \mathrm{b}($ ro $)$, (left) demonstrate the positions $\left(r_{1-3} ; r o_{1-3}\right)$ of the NDE. The larger is the difference between $\mathrm{D}_{\mathrm{B}^{-}}$ $\mathrm{D}_{\mathrm{C}}$ the more effective is the influence of the NDE for the fast $\mathrm{X}_{\mathrm{B}^{-}}$concentration wave (see the influence of the $\mathrm{D}_{\mathrm{B}}$-value on the integral kinetic maximum $\mathrm{F}_{\mathrm{B}}{ }^{\max }\left(\mathrm{T}_{\mathrm{m}}\right)$ in Figs. 4a, $\mathrm{b}$ (left to right $)[3,7,8]$.

The results of the computerized simulations in Figs.3a,b demonstrate that the mentioned condition $\left(\mathrm{D}_{B}>>\mathrm{D}_{C}\right)$ for the $\mathrm{D}_{i}$-diffusivities of the $\mathrm{X}_{2 \mathrm{~B}}, \mathrm{X}_{3 \mathrm{C}}$-concentration waves is not enough for the occurrence of the distinct kinetic peak $\left(\mathrm{F}_{B}{ }^{\max }\right.$-value) on the nonmonotonous $\mathrm{F}_{\mathrm{B}}(\mathrm{T})$-curve. The $\mathrm{F}_{\mathrm{B}}{ }^{\mathrm{max}}$-peak value depends essentially also on the $\mathrm{D}_{\mathrm{A}^{-}}$ diffusivity of the outgoing $\mathrm{X}_{1 \mathrm{~A}}$-concentration wave which exits from the IEx r,ro-matrices. The larger is the $\mathrm{D}_{\mathrm{A}}$-diffusivity the higher is the peak $\left(\mathrm{F}_{B}{ }^{\max }\right)$ in the $\mathrm{F}_{\mathrm{Br} . \mathrm{ro}}(\mathrm{T})$-curves (compare Figs. $4 \mathrm{a}(r), \mathrm{b}(r o),(1-3)$, or $5 \mathrm{a}(r), \mathrm{b}($ ro $)(1-3))$.

The faster $\mathrm{X}_{\mathrm{A}}$-concentration wave moves out of the IEx r,ro-matrix the smaller is the influence of the outgoing $\mathrm{X}_{\mathrm{A}}$-concentration wave on the total wave interference (which activated the NDE effect) in the ternary IEx system considered (see Figs.5a,b presenting the influence of the $\mathrm{D}_{\mathrm{A}}$-diffusivity value).

It means that the interference of the three diffusion $\mathrm{X}_{i}$-concentration waves $\left(i={ }_{1} \mathrm{~A},{ }_{2} \mathrm{~B},{ }_{3} C\right)$ in the IEx matrix plays the main role in the behavior of the integral kinetic $\mathrm{F}_{B \mathrm{r}, \mathrm{ro}}(\mathrm{T})$-curves ( see Figs. 3a,b(right), and Figs.4a,b; 5a,b).

The necessary conditions for the intensive NDEffect are determined by the inequality relation for the all three $\mathrm{D}_{i}$-diffusivities: notably, $\left(\mathrm{D}_{\mathrm{B}}, \mathrm{D}_{\mathrm{A}}\right)>>\mathrm{D}_{C}$. Thus under the certain conditions (i.e., for the big difference in the diffusivities $\mathrm{D}_{B}>>\mathrm{D}_{C}$ ) the $\mathrm{X}_{\mathrm{B}^{-}}$ concentration is accumulated exactly in the region of zero value $\left(\mathrm{X}_{\mathrm{C}} \sim 0, \mathrm{~V}_{1-3}\right.$ verticals in Figs. 3a,b, left, mentioned) of the frontal part of the invading slow $\mathrm{X}_{\mathrm{C}}$-concentration wavedisplacer (see X2 $2_{B r} ; X_{2 B r o}$-profiles, (2B-curves, dashed blue, Figs. 3a,b,| left - $\left.\mathrm{X}_{i r, r o}\right\}$ ).

For the ternary IEx kinetics the NDE effect in the $\mathrm{X}_{\mathrm{B}}$-concentration waves brings the appearance of the kinetic maximum $\left(\mathrm{F}_{\mathrm{Br}}{ }^{\max } \sim \mathrm{F}_{\mathrm{Bro}}{ }^{\max }\right)$ for both r,ro-cases (dot $(\bullet)$ in Figs.3a,b; $\mathrm{F}_{\mathrm{B}}{ }^{\max }$-right). The detailed estimations of the influence of the $\left\{\mathrm{D}_{\mathrm{B}}, \mathrm{D}_{\mathrm{A}}\right\}-$ Diffusivities on the integral kinetic $\mathrm{F}_{\mathrm{B} r, r o}{ }^{\max }$ is presented in this Section (S.5.2). In the computerized simulation a number of the ternary nonselective IEx systems have been considered describing the non-monotonous kinetic $F_{B}(T)$-behavior in dependence of the $D_{B}, D_{A^{-}}$ diffusivities for the non-selective IEx matrix of various shapes (r-bead, ro-fiber). [3,7,8]

The computerized modeling of the nonselective IEx systems behavior has been realized for a number of variants with the wide diapason of the $\mathrm{D}_{\mathrm{B}}, \mathrm{D}_{\mathrm{A}}$-diffusivity values on the basis of the author's computer Fortran programs. There were calculated the $\mathrm{X}_{i \mathrm{r}(\mathrm{ro})}(\mathrm{T})$ waves (profiles) moving along the $r,(r o)$-distances in course of time (T). The calculated results are presented «in line \& abreast» via the «coupled pictures» method (S5.1): \{left$\mathrm{X}_{i r, \mathrm{ro}} \mid \mathrm{F}_{i r, \mathrm{ro}}$-right $\}$ (like in Figs. 3a,b) with the kinetic $\mathrm{F}_{i r, r o}(\mathrm{~T})$-curves $(r i g h t) .[3,7,8]$ 
During the modeling the propagating $\mathrm{X}_{i}(\mathrm{r}, r o$; $\mathrm{T})$-waves $\left(l e f t-\mathrm{X}_{i r, r o}\right.$; Figs.3a,b) have been computed simultaneously along with the corresponding integral kinetic $\mathrm{F}_{i r, r o}(\mathrm{~T})$ curves (Figs.3a,b, $\mathrm{F}_{i r, r o}$-curves, right).

The non-monotonous kinetic $\mathrm{F}_{\mathrm{B} r, r o}(\mathrm{~T})$-curves behavior in dependence of the $\left\{D_{B}, D_{A}\right\}$-values is presented in Figs. $4 \mathrm{a}, \mathrm{b}$ for the various $\mathrm{D}_{\mathrm{B}}{ }^{1-3}$-dependence. Figures $5 \mathrm{a}, \mathrm{b}$ represent the analogical non-monotonous kinetic $\mathrm{F}_{\mathrm{B} r, r o}(\mathrm{~T})$-curves behavior for the various $\mathrm{D}_{\mathrm{A}}{ }^{1-3}$-dependence $[3,7,8]$. For the kinetic $F_{\mathrm{B}}(\mathrm{T})$-curve there is demonstrated the reduction of the $\mathrm{F}_{\mathrm{B}}{ }^{\max }$-accumulation with the decrease of the $\mathrm{D}_{B}$-values (Figs. $4 \mathrm{a}, \mathrm{b}, \mathrm{D}_{\mathrm{B}}{ }^{1-3}$-variation, from left to right),

The same $F_{\mathrm{B}}(\mathrm{T})$-curve kinetics behavior takes place for the decrease of the $\mathrm{D}_{\mathrm{A}^{-}}$- diffusivity values (Figs. 5a,b, $\mathrm{D}_{\mathrm{A}}{ }^{1-3}$-variation, from left to right).

The decrease of the $\mathrm{F}_{\mathrm{B} r \text { ro }}{ }^{\text {max }}$-values for :

1. $\mathrm{D}_{\mathrm{B}}{ }^{1-3}$ - variable, (from large $\mathrm{D}_{\mathrm{B}}{ }^{1}$ till small $\mathrm{D}_{\mathrm{B}}{ }^{3}$ ), Figs. 4a,b;

2. $\mathrm{D}_{\mathrm{A}}^{1-3}$ - variable, (from large $\mathrm{D}_{\mathrm{A}}{ }^{1}$ till small $\mathrm{D}_{\mathrm{A}}^{3}$ ), Figs. 5a,b

means the corresponding reduction of the NDE effect with the reduction of the ${ }_{2} \mathrm{~B}$ accumulation which is described by the $\mathrm{F}_{\mathrm{B} r, r o}{ }^{\max }$-value discussed above (Figs. 4a,b \&5,b).

Consequently it is seen that the reduction of the peak (from $\mathrm{F}_{B r, r o}{ }_{\text {max }}$ to $\mathrm{F}_{B r, r o}{ }^{\text {fin }}$ ) with the further decrease of the $\mathrm{D}_{\mathrm{B}}\left(\right.$ or $\left.\mathrm{D}_{\mathrm{A}}\right)$ values (till $\left.\sim 0.05\right)$ the transition for the $\mathrm{F}_{\mathrm{B} r, r o}$-curves takes place to the usual monotonic behavior of the $\mathrm{F}_{\mathrm{B} r, r o}(\mathrm{~T})$-curves (Figs. 4, and Figs.5, right,3r,3ro-curves).

(a) r-bead

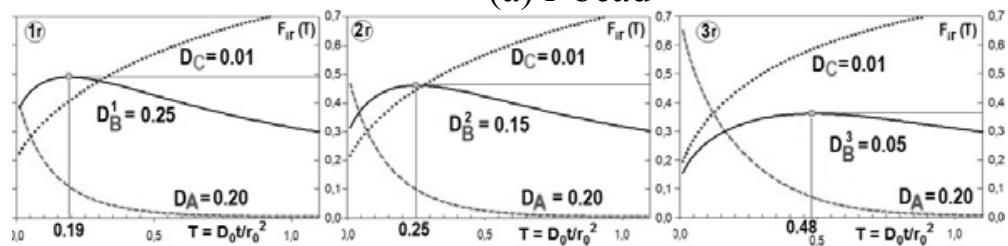

(b) ro-fiber

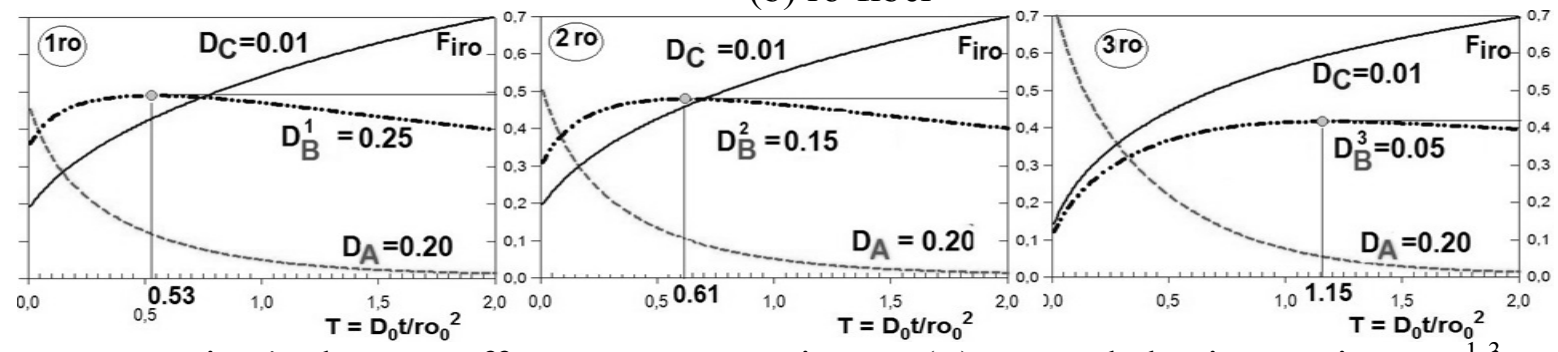

Fig. $4_{8} \mathrm{a}$,b. NDE effect, non-monotonic $\mathrm{F}_{\mathrm{Br}, \mathrm{ro}}(\mathrm{T})$-curves behavior. Various $\mathrm{D}_{\mathrm{B}}{ }^{1-3}$ values: $\mathrm{D}_{\mathrm{B}}=0.25$ (left); 0.15(middle); 0.05(right) colored $(\bullet)\left\{\mathrm{T}_{\mathrm{mr}, \mathrm{ro}} ; \mathrm{F}_{\mathrm{B} r, r o}{ }^{\max }\right\}$;

$\mathrm{F}_{\mathrm{Br}, \mathrm{ro}}(\mathrm{T})$-curves (blue, dashed). $\mathrm{D}_{\mathrm{A}}=0.20 ; \mathrm{D}_{\mathrm{C}}=0.01$;

(a) r-bead, $\mathrm{T}_{\mathrm{mr}}=0.19(1 \mathrm{r}), 0.25(2 \mathrm{r}), 0.48(3 \mathrm{r})$;

(b) ro-fiber, $\mathrm{T}_{\mathrm{mro}}=0.53(1 \mathrm{ro}), 0.61(2 \mathrm{ro}), 1.15(3 \mathrm{ro})$.

Thus it is seen that the decrease of the $\mathrm{D}_{\mathrm{B}}\left(\right.$ or $\mathrm{D}_{\mathrm{A}}$ ) diffusivity reduces the NDE effect till its absence (when $\mathrm{D}_{B}\left(\right.$ or $\left.\mathrm{D}_{\mathrm{A}}\right)$ reaches $\sim 0.05$ value). When diffusivities $\mathrm{D}_{\mathrm{B}}\left(\right.$ or $\left.\mathrm{D}_{\mathrm{A}}\right)$ are smaller than $(\leq 0.05)$ the unusual non-monotonous kinetic $\mathrm{F}_{\mathrm{Br}, \mathrm{ro}}(\mathrm{T})$-curves behavior is impossible (Figs. 4a,b\& 5a,b, right side) even for the big $\mathrm{D}_{\mathrm{A}}\left(\right.$ or $\left.\mathrm{D}_{\mathrm{B}}\right)$ value.

In these cases (concerning NDE estimation): when the relation $\left(\mathrm{D}_{A}, \mathrm{D}_{B}\right) \sim \mathrm{D}_{C}$ is maintained then the NDE effect disappears. The explanation for the loss of the NDE effect is rather simple: due to the relation $D_{B} \sim D_{C}$ the $X_{B, C}$-concentration waves move not far from each other (in other words for the two ${ }_{2} \mathrm{~B},{ }_{3} \mathrm{C}$-waves their discrepancy don't take place). 
Therefore the three ${ }_{2} \mathrm{~B},{ }_{3} \mathrm{C},{ }_{1} \mathrm{~A}$-concentration waves interfere together almost synchronously. In result the NDE effect is minimal for the $\mathrm{X}_{\mathrm{Br}, \mathrm{ro}}$-concentration wave displaced with the absence of the $\mathrm{F}_{\mathrm{Br} \text {,ro }}{ }^{\max }$, and with the trend to the usual monotonic (increasing) behavior of the $\mathrm{F}_{\mathrm{Br}, \mathrm{ro}}$-curves.

In the results of the computerized MMT,IEx kinetics simulations Figures 4a,b, $\left(\mathrm{D}_{B}{ }^{3} \sim 0.05\right.$, right $)$, and Figures $5 \mathrm{a}, \mathrm{b},\left(\mathrm{D}_{\mathrm{A}}{ }^{3} \sim 0.05\right.$, right $)$ confirm these rather clear and understandable conclusions.

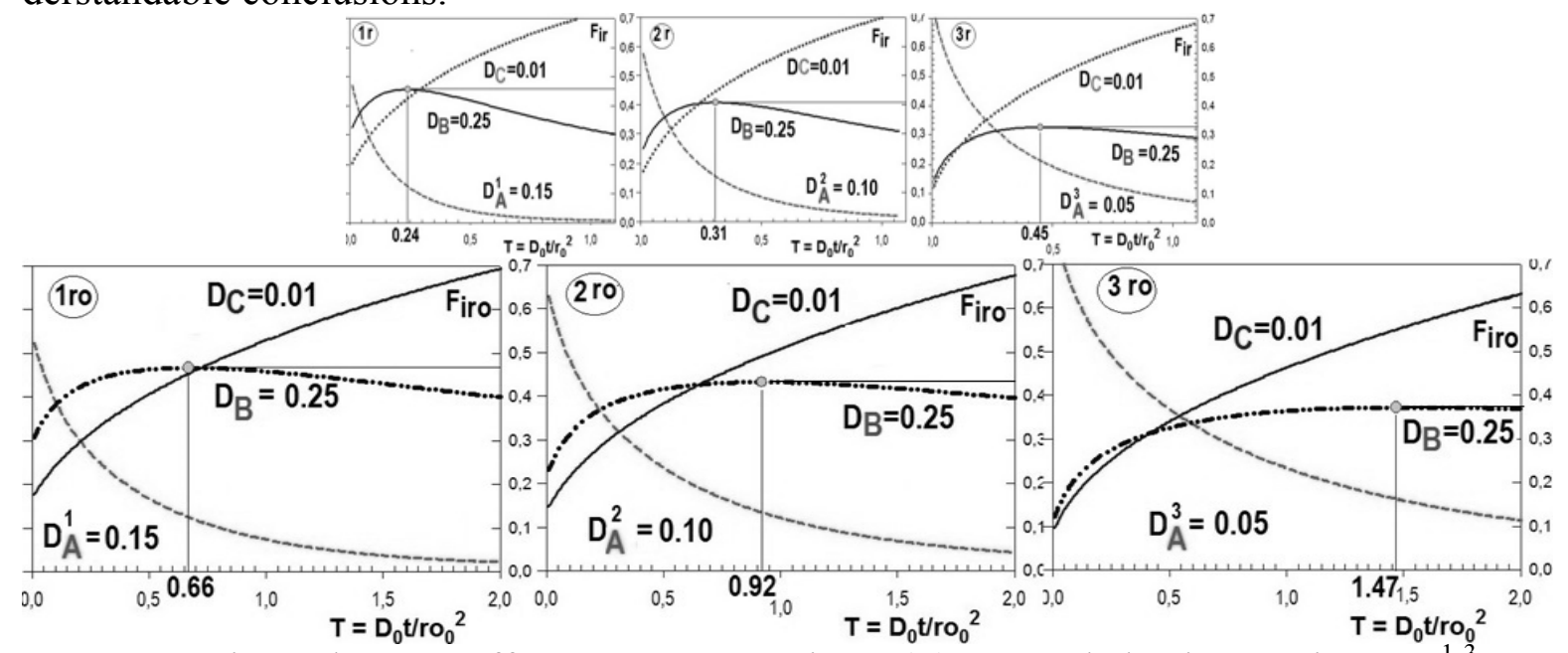

Fig. 5a,b. NDE effect; non-monotonic $\mathrm{F}_{\mathrm{B}}(\mathrm{T})$-curves behavior. Various $\mathrm{D}_{\mathrm{A}}{ }^{1-3}$ values. The colored $(\bullet)\left\{\mathrm{T}_{\mathrm{m} r, r o} ; \mathrm{F}_{\mathrm{Br}, \mathrm{ro}} \max \right\}$ in $\mathrm{F}_{\mathrm{B} r, r o}(\mathrm{~T})$-curves (blue, dashed). $\mathrm{D}_{\mathrm{B}}=0.25 ; \mathrm{D}_{\mathrm{C}}=0.01 ; \mathrm{D}_{\mathrm{A}}=0.15$ (left); 0.1(middle); 0.05(right).

(a) r-bead, $\mathrm{T}_{\mathrm{mr}}=0.24(1 \mathrm{r}), 0.31(2 \mathrm{r}), 0.45(3 \mathrm{r})$;

(b) ro-fiber, $\mathrm{T}_{\mathrm{mro}}=0.66(1 \mathrm{ro}), 0.92(2 \mathrm{ro}), 1.47(3 \mathrm{ro})$.

\section{Conclusions}

The new generalized theoretical results of the MMT kinetics for the nonselective IEx (S.6) r,ro-matrices are determined by the interference of the propagating multicomponent $\mathrm{X}_{(i)}$ (distance; T-time)-concentration waves on the basis of the fundamental key wave, $\mathrm{W}^{+}$-concept. The wave $\mathrm{W}^{+}$-concept unites here the two subjects of the theoretical investigations in the manuscript: (a) MMT, IEx kinetics (S.6 with 6.1 conclusions), and (b) Visualization of the MMT, IEx kinetics (S.,5; S.6.2 conclusions).

\section{IEx matrices \\ 6.1. Nonselective MMT kinetics in the nonselective $\left\{D_{i}\right\}$-diffusion}

By the computerized modeling there is demonstrated that the NDE effect between the two invading ${ }_{2} \mathrm{~B},{ }_{3} \mathrm{C}$-concentration waves takes place in the IEx r,ro-matrices. In the result of the computerized simulation of the ternary IEx kinetics process the NDE effect (i.e. the displacer, slow $\mathrm{X}_{\mathrm{C}}$-concentration wave displaces the fast $\mathrm{X}_{\mathrm{B}}$-wave displaced, S.5.1) leads to the ${ }_{2} \mathrm{~B}$-accumulation which reaches the $\mathrm{F}_{\mathrm{B}}{ }^{\mathrm{m}}$-maximum in the non-monotonous kinetic $\mathrm{F}_{\mathrm{B}}$-curve (after the specified $\mathrm{T}_{\mathrm{m}}$-time).

Thus in the result the non-monotonous behavior of the kinetic $\mathrm{F}_{\mathrm{B}}(\mathrm{T})$-curve is conditioned by the New Displacement Effect demonstrated and considered in Figs.3a(r),b(ro). In S.5 it is proved obviously that the NDE effect during the $\mathrm{X}_{i}$-concentration waves interference is the straight reason of the non-monotonous $\mathrm{F}_{\mathrm{B}}(\mathrm{T})$-curve behavior (including the kinetic $\mathrm{F}_{\mathrm{B}}{ }^{\max }$-value). The interference of the propagating $\mathrm{X}_{i}$-concentration waves 
$\left(i={ }_{1} \mathrm{~A}, 2 \mathrm{~B},{ }_{3} \mathrm{C}\right)$ with the NDE effect is the theoretically substantiated reason for the nonstandard, non-monotonous kinetic $\mathrm{F}_{\mathrm{B}}$-curve behavior.[3,7,8]

The NDE effect for the $\mathrm{X}_{i \mathrm{r}, \mathrm{ro}}(\mathrm{T})$-concentration waves (together with the nonmonotonous kinetic $\mathrm{F}_{\mathrm{B}}(\mathrm{T})$-curve behavior) is demonstrated visually in well understandable manner by the original method of the theoretical presentation via the «coupled pictures» in line and abreast: $\left\{\right.$ left- $\mathrm{X}_{\boldsymbol{i}}$ waves $\mid \mathrm{F}_{\boldsymbol{i}}$-curves, right $\}$. The «coupled pictures» $\left(\mathrm{X}_{i} \mid \mathrm{F}_{i}\right)$ synchronized are arranged «in line \&abreast» (as in Figs.3a(r),b(ro)). The corresponding nonmonotonous kinetic $\mathrm{F}_{\mathrm{B}}(\mathrm{T})$-curve with the unusual behavior in the course of time $(\mathrm{T})$ takes place in dependence of the $\left\{\mathrm{D}_{i}\right\}$-Diffusivities relations $\left\{\mathrm{D}_{\mathrm{A}} \sim \mathrm{D}_{\mathrm{B}}>>\mathrm{D}_{\mathrm{C}}\right\}(\mathrm{S} .5 .2)$.

\subsection{Visualization of the waves $\left(\mathrm{W}^{+}\right)$with the results by the author's SCAnimations («SCA.avi» videofiles) method}

The both variants of the NC\&IEx MMT kinetics processes inside the NC([1-5]) \&IEx $([3,7,8]$ including the S6.1 here) r,ro-matrices with the new theoretical results are visualized and provided obviously by author via the contemporary method of the visualization of the results of the computerized modeling, i.e. via the multi-colored computerized SCAnimations: namely the «SCA.avi» video-files.

The «SCA.avi» video-files are assembled (by the author) sequentially via the separate «frames» (arranged in course of T-time for the MMT process): «pictures» [1-5] or «doubled pictures» (as in Figs. 3a(r),b(ro) for IEx [3,7.8]) in the usual «animation pattern». The computerized SCAnimations scanning are executed via the «SCA.avi» multi-colored video files. For the manuscript considered the computerized SCAnimations demonstrate

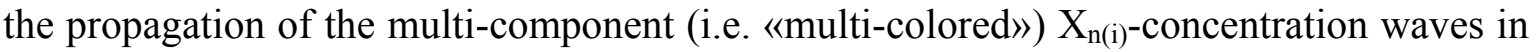
spatial coordinates (ro,r-distances) in the course of T-time during the MMT kinetics processes inside the (bi-functional NC) \&(nonselective IEx) r,ro,L-matrices (Figs.3a,b are the frames-pictures for the corresponding SCAnimations).

Such multi-colored SCAnimation (SCA.avi) videofiles demonstrations of the MMT processes during the oral computerized presentation (at the conferences in particular) are well perceived and understandable by the sci. audience. The SCA method has been used permanently for the implementation of the «SCA.avi» into the various oral thematic presentations by the author of the manuscript during a long-continued period of time (more than 14 years) for the demonstration of the results of the presented theoretical studies (on the basis of the fundamental key wave $\mathrm{W}^{+}$-concept) in the multicomponent kinetics \& dynamics (chromatography) of the MMT systems.[1-5,17-19,32]

SCAnimations (as the prepared «SCA.avi» video files) have been used by author with the permanent experience in the effective, easily, and visually perceptible presentations of the MMT kinetics (and dynamics) processes[1-5,7,8,17-19,32] in many International Conferences (including in particular the regular Conferences «IEX 2004, 2008, 2012»"», Cambridge, UK[18,19,32]).

The interferences of the $X_{n}$-concentration waves have been shown visually during the MMT dynamics and kinetics by the pictorial presentations including the author's multicolored SCAnimations ( «SCA.avi») for a number of the International Conferences [for example 18,19,32].

The NDE effect with the interference of the $\mathrm{X}_{\mathrm{B}}, \mathrm{X}_{\mathrm{C}}$-concentration waves is shown by the author's SCAnimations including the «coupled pictures» (left) disposed «in line and abreast» together with the kinetic $\mathrm{F}_{\mathrm{Br}, \mathrm{ro}}(\mathrm{T})$-curve (right) demonstrating its unusual, and non-monotonous behavior. [3,7,8] The origin, location, and visual presentations of the NDE effect via the obvious coupled pictures (disposed «in line and abreast») have been demon-

Калиничев А.И. / Сорбционные и хроматографические процессы. 2017. Т. 17. № 2 
strated effectively especially via the author's multi-colored SCAnimations ( $« S C A$.avi») video files).

The visual demonstration of the bi-functional NC, MMT kinetics are prepared via the ( $\langle S C A$.avi» video-files) as the results of the computerized mathematical modeling with the propagating and calculated $\mathrm{X}_{i}$-concentration multi-colored profiles-waves obtained for the successive time $\left(\mathrm{T}^{\mathrm{S}}\right)$ moments[1-5,7,8,18,19,32].

The same approach has been used for the non-selective ternary IEx kinetics with using as the frames: «coupled pictures» (principal examples are in Figs. $3 \mathrm{a}(r), \mathrm{b}(r o)$ ) in the author's SCAnimations with the demonstration of the NDE effect[3.7.8].

\section{References}

1. Kalinitchev A, Advances in Nanoparticles. AnP.Sci.Res.Publ.: SCIRP. E-Journal., 2013, No 2(2), pp. 1-18. (Site ANP: http://www.scirp.org/ journal/anp/).

2. Kalinitchev A, Prot. Met.\&Phys. Chem. Surf. (Springer Ed.), 2013, Vol. 49(6), pp. 627638 (Site Springer: http://www. springerlink. $\underline{\mathrm{com} /}$ openurl.asp?genre $=$ article\& id $=$ doi: 10.1134/S2070205113060051).

3. Kalinitchev A, Rev (NTREV). Special issue (N5) "NanoTechnology: from Convergence to Divergence", DeGruyter Ed., 2014, Vol. 3(5), pp. 467-498. http://degruyter.com/new /ntrev2014.3issue-files.doi:10.1515/ntrev-20140007. Publ. on line 8.10.2014 (Ed. Ja S. Lee). NTREV(2014).

4. Kalinitchev A, Sorbtsionnye i khromatograficheskie protsessy, 2016, Vol. 16, No 6, pp. 748-780.

5. Kalinitchev A., New model of multicomponent mass transfer kinetics in bi-functional matrix of nanocomposites and results of simulation. Prot. Met.\&Phys. Chem. Surf. (Springer Edition), 2013, Vol. 49 (6), pp. 627-638. (Engl.). (Site Springer :http://www. springerlink. com/ openurl. asp?genre $=$ article \& id $=$ doi: 10.1134/S2070205113060051).

6.Haase R, Thermodynamics of Irreversible Processes.Ch.2;4.M., Mir, 1967, P.544.

7. Kalinitchev A., Universal Journal of Physics and Application, 2013, Vol. 1(2), pp. 130143. Doi: 10.13189/ujpa.2013.010213.

8. Kalinitchev A., Sorbtsionnye i khromatograficheskie protsessy, 2014, Vol. 14, No 5, pp. 744-759.

9. Helfferich F., Klein G, Multicomponent Chromatography. Theory of Interference, New York M. Dekker Inc., (1970). 360 p.

10. Helfferich F, Coherence : Power and Challenge of a new Concept. New direction in Ad- sorption Technology. G.Keller ed., Butterworth. Boston, 1989, pp 1-11.

11. Industrial \& Engineering Chemistry Research. J. (F. Helfferich Festschrift), J. Am. Chem. Soc, 1995, Vol. 34, pp. 2551-2922. doi:10.1021/ie00047a029.

12. Tondeur D., Bailly M, Chem. Eng. Process, 1987, Vol. 22, pp. 91-105. doi:10.1016/ 0255-2701(87)80035-1.

13. Tondeur D, Ind. \& Eng. Chem. Res., 1995, Vol. pp. 2782-2788. doi:10.1021/ie00047a029.

14. Hwang YL., Ind.\&Eng.Chem.Res., 1995, Vol. 34, pp. 2849-2864. doi:10.1007/978-94009-85797:10.1021/ie00047 a039,

15. Percolation Process: Theory and Applications. ed.: Rodrigues, AE, Tondeur, D, The Hague: Sijthoff \& Nordhoff, 1981. doi:10.1007/978-94-009-8579-7.

16. Kalinitchev A., J. Rus. Chem. Reviews., 996, Vol. 65, pp. 95-115. doi:10.1070/RC1996v065n02A BEH000201.

17. Hoell W and Kalinichev A, J. Rus. Chem. Reviews, 2004, Vol. 73, pp. 351-370. (Rus \& Engl).doi:10.1070/RC2004v073n04ABEH0007 68.

18. Kalinitchev A., Hoell W, in IEX2004, Ion Exchange Technology for Today and Tomorrow, ed:M. Cox, Society of Chemical Industry, London, 2004, pp. 53-58.

19. Kalinitchev A., Hoell W, in IEX2008, Recent Advances in IEx Theory\&Practice, ed:M.Cox, Society of Chemical Industry, London, 208, pp. 85-93.

20. Helfferich F, Ion Exchange. Mc.GrawHill. NY. Ch.6., 1962. (Ionen Austauscher, Verlag Chemie, GMBH, 1959, Deutsch).

21. Helfferich F, Ion Exchange Kinetics. Ch.5. in Ion Exchange (A series of Adv.) ed. Ja.I. Marinsky). St. Univ. NY., 1966.

22. Helfferich F, Ion exchange kinetics - evolution of a theory. in: "Mass Transfer \& Kinet- 
ics of IEx" (ed: L.Liberti\&F.Helfferich) 28. Yoshida H, Kataoka T, J. Chem. Eng., M.Sijthoff \& Nordhoff . The Hague, 1983, pp. 1988, Vol. 39, pp. 55-62.

157-179. doi:10. 1007/978-94-009-6899-8_6.

29. Courant R and Friedrichs K, Supersonic

23. Petruzelli D, Helfferich F, Liberti L, Millar flow and Shock Waves, Springer, 1999, $464 \mathrm{P}$.

J. et al., Reactive Polymers, 1987, Vol. 7, pp. 113.

30. Prigogine I., Herman R, Kinetic Theory of Vehicular Traffic, NY., Elsevier, 1971, 55 p.

24. Kalinitchev A., IEx \& Solv. Extr., 1995, Vol. 12, M.Dekker, Ch.4, pp. 149-196.

31. Whitham G, Linear and Nonlinear waves, Wiley, NY, 1974, 636 p.

25. Helfferich F., Hwang Y-I, Am. I. Ch.E. Symp. Ser., 1985, Vol. 81, pp. 7-27.

26. Hwang Y-I, Helfferich F, Reactive Polymers, 1987, Vol. 5, pp. 237-252.

27. Yoshida H, Kataoka T, J. Ind. Eng. Chem. Res., 1987, Vol. 26(6), pp. 1179-1184.

Калиничев Анатолий Иванович -д.х.н. (физ. химия), гл. научный сотрудник Института физ химии и электрохимии им. акад. А.Н. Фрумкина РАН, Москва.

32. Kalinitchev A, in IEX2012,ed: M. Cox, Society of Chemical Industry, London, S. Fundam. p 1-18, (2012). e-book (The Intern. IEx 2012 Confer." Thesis, pp. 123-124.

33. Dolgonosov A, Khamisov R, Krachak A., Prudkovskiy A, React. Func. Polymers, 1995, Vol. 28, pp.13-20.

Kalinitchev Anatoliy I. - Doctor Habilitat (Phys. Chem.), principal investigator, Institute for Phys Chemistry and ElectroChemistry named after acad. A.N. Frumkin. RAS (Moscow). E-mail: kalina@phyche.ac.ru 